\author{
Federal Reserve Bank of Dallas \\ Globalization and Monetary Policy Institute \\ Working Paper No. 254 \\ http://www.dallasfed.org/assets/documents/institute/wpapers/2015/0254.pdf
}

\title{
Catalytic IMF? A Gross Flows Approach*
}

\author{
Aitor Erce \\ European Stability Mechanism \\ Daniel Riera-Crichton \\ Bates College
}

November 2015

\begin{abstract}
The financial assistance the International Monetary Fund (IMF) provides is assumed to catalyze fresh investment. Such a catalytic effect has, however, proven empirically elusive. This paper deviates from the standard approach based on the net capital inflow to study instead the IMF's catalytic role in the context of gross capital flows. Using fixed-effects regressions, instrumental variables and local projection methods, we find significant differences in how resident and foreign investors react to IMF programs as well as in inward and outward flows. While IMF lending does not catalyze foreign capital, it does affect the behavior of resident investors, who are both less likely to place their savings abroad and more likely to repatriate their foreign assets. As domestic banks' flows drive this effect, we conclude that IMF catalysis is "a banking story". In comparing the effects across crisis types, we find that the effect of the IMF on resident investors is strongest during sovereign defaults, and that it exerts the least effect on foreign investors during bank crises.
\end{abstract}

JEL codes: F32, F33, F36, G01, G15

\footnotetext{
* Aitor Erce, European Stability Mechanism, 6a Circuit de la Foire Internationale, 1347 Luxembourg. 352-621345617. aerce@esm.europa.eu. Daniel Riera-Crichton, Bates College, Pettengill Hall, Lewiston, Maine 04240. 207-786-8296. drieracr@bates.edu. We thank A. Bonfiglioli, A. Fernandez, P. Fioretti, N. Funke, A. Gilbert and seminar participants at European Stability Mechanism, International Risk Management Conference 2015, OeNB Conference on Macro-Financial Linkages and Current Account Imbalances, and 2015 Barcelona GSE Summer Forum for their comments, M. de las Casas and X. Serra for sharing their dataset on IMF agreements, and S. Esarey for superb editorial assistance. The views in this paper are those of the author and do not necessarily reflect the views of the European Stability Mechanism, the Federal Reserve Bank of Dallas, or the Federal Reserve System.
} 


\title{
Catalytic IMF? A Gross Flows Approach*
}

\author{
Aitor Erce ${ }^{\dagger} \quad$ Daniel Riera-Crichton ${ }^{\ddagger}$
}

\begin{abstract}
The financial assistance the International Monetary Fund (IMF) provides is assumed to catalyze fresh investment. Such a catalytic effect has, however, proven empirically elusive. This paper deviates from the standard approach based on the net capital inflow to study instead the IMF's catalytic role in the context of gross capital flows. Using fixed-effects regressions, instrumental variables and local projection methods, we find significant differences in how resident and foreign investors react to IMF programs as well as in inward and outward flows. While IMF lending does not catalyze foreign capital, it does affect the behavior of resident investors, who are both less likely to place their savings abroad and more likely to repatriate their foreign assets. As domestic banks' flows drive this effect, we conclude that IMF catalysis is "a banking story". In comparing the effects across crisis types, we find that the effect of the IMF on resident investors is strongest during sovereign defaults, and that it exerts the least effect on foreign investors during bank crises.
\end{abstract}

Keywords: IMF, catalysis, residence, capital flows

JEL codes: F32, F33, F36, G01, G15

\section{Introduction}

Many crises feature, as part of the resolution strategy, the involvement of the International Monetary Fund (IMF). In such cases, the Fund takes on the role of an international lender of last resort and provides crisis-hit economies with subsidized funding, provided those countries implement a macroeconomic adjustment program. The financial assistance is designed to give the economies breathing space in which to solve their temporary financing problems.

This approach has both critics and supporters. The Fund itself defends this strategy by arguing that it reassures private creditors that the exit from the

\footnotetext{
${ }^{*}$ We thank A. Bonfiglioli, A. Fernandez, P. Fioretti, N. Funke, A. Gilbert and seminar participants at European Stability Mechanism, International Risk Management Conference 2015, OeNB Conference on Macro-Financial Linkages and Current Account Imbalances, and 2015 Barcelona GSE Summer Forum for their comments, M. de las Casas and X. Serra for sharing their dataset on IMF agreements, and S. Esarey for superb editorial assistance. These are the authors' views and are not to be reported as those of The European Stability Mechanism.

$\dagger$ European Stability Mechanism

$\ddagger$ Bates College
} 
crisis will be orderly, reducing the potential for a drastic reaction (Cottarelli and Giannini, 2002). An extensive literature has assessed the importance of the so-called catalytic effect of official financing by looking at the net flow of capital entering/exiting countries under an IMF program. On the theoretical front, Corsetti et al., (2006) and others have shown that IMF lending has the potential to catalyze foreign capital inflows But disconcertingly, from an empirical perspective, many studies cast doubt on the existence of any such positive effect. Critics have seized upon this lack of empirical evidence to argue that Fund policies are too restrictive and generate moral hazard on both debtors and creditors (Birds and Rowlands, 2002). ${ }^{1}$

In parallel, the literature on capital flows has recently turned its focus to the gross components of the financial account. According to this literature, the gross flows composing a country's net capital inflow react dissimilarly to different factors. Along these lines, Forbes and Warnock (2012) and Broner et al. (2013) show that resident and foreign investors' reaction functions are distinct. $^{2}$ These papers demonstrate that gross capital flows are very large and volatile, especially relative to net capital flows. They also shed light on the sources of fluctuations driving capital flows by proving that crises can affect domestic and foreign agents asymmetrically.

In this paper, we bridge these two literature strands by looking at the catalytic effect of IMF lending through the lenses of the gross flows composing the current account. We distinguish varieties of capital flows entering and exiting an economy and study how they react to the signing of an IMF program. We follow Broner et al. (2013) and separate flows according to the investors' residence. Additionally, as in Janus and Riera-Crichton (2015), we study the effect of official funding on a breakdown of capital flows into and out of an economy, regardless of the nationality of investors. The contrasting experiences of Uruguay (2002) and Turkey (2005) after their respective IMF programs were signed exemplify the relevance of our approach. As shown in Graph 1, resident and foreign investors reacted markedly differently in these two instances. In Turkey, after the IMF agreement was signed, the foreign inflow continued unabated and residents retrenched only briefly. In contrast, in Uruguay, after the signing, significant foreign capital took flight. Fortunately, residents' investment pattern also changed and cushioned in part the effects of that flight; after the program signing, they started repatriating a significant amount of their savings placed abroad.

To obtain more systematic and robust evidence regarding the role of IMF lending on gross capital flows, we have compiled a detailed dataset of IMF interventions and quarterly gross capital flows for over 50 economies. We use it to analyze whether IMF program signings have distinct effects on gross flows. Non-random selection into official support obscures the interpretation of the relation between official credit and gross capital flows. We tackle this concern

\footnotetext{
${ }^{1}$ IMF (2013) argues that the provision of official financing can crowd out private financing, potentially creating an anti-catalytic effect.

${ }^{2}$ This is also the case for inward and outward flows (see Janus and Riera-Crichton, 2015).
} 
by employing an instrumental variables approach. We follow Barro and Lee (2005) and a large literature on the political and geo-strategic determinants of IMF lending. This literature provides us with an easy and powerful way of instrumenting official support programs. Additionally, we use a linear local projections method (Jorda, 2005) to gauge the dynamic reaction of the various types of capital flows to the enactment of IMF programs.

Our results show significant differences in how resident and foreign investors react to IMF programs. While the IMF appears unable to catalyze foreign capital, substantial evidence shows that it does affect the behavior of resident investors. Remarkably, the strength of the effect of IMF loans on resident investors' behavior is such that we find evidence of both more muted domestic capital flight and an increased repatriation of residents' savings placed abroad. When we look at the reaction by types of flows, we find that most of the catalytic effect relates to domestic banking flows, making us conjecture that IMF catalysis is "a banking story". Finally, using a non-linear approach in our local projection estimates, we show that the type of crisis the IMF program is fighting affects the degree to which both resident and foreign investors react. The IMF appears to be better able catalyze domestic savings during sovereign defaults and has the least effect on foreign investors during bank crises.

\section{Catalytic IMF Lending: A review of the litera- ture}

Defenders of the catalytic effect argue that, by reassuring private creditors about the existence of an ordered exit from a crisis, these interventions can stimulate private flows when most needed. A number of theoretical contributions support this positive view. Corsetti et al. (2006) and Morris and Shin (2006) contend that IMF lending is able to reduce the incidence of panic-driven liquidity crises. Similarly, Peñalver (2004) shows that subsidized lending can induce the borrowing country to exert effort to avoid default. By raising future rates of return on investment, official lending encourages larger private capital flows. De Resende (2007) shows that if conditionality forces countries to save more, the resulting lower probability of default can encourage private lenders to relax their borrowing constraints. Instead, opponents argue that such policies generate moral hazard both for debtors and creditors, and that the Fund's seniority status is detrimental to the debtor-creditor relationship as it might dilute private obligations (Saravia, 2013). In a framework of panic-driven liquidity runs, Zwart (2007) qualifies the results in Corsetti et al. (2006) by showing that catalysis may not materialize given that, through its signaling effect, IMF support can trigger capital flight. ${ }^{3}$

An extensive literature has studied empirically the significance of the IMF's catalytic effect, delivering at best mixed evidence. Critics have seized upon this lack of empirical evidence to argue that an overestimation of its catalytic

\footnotetext{
${ }^{3}$ Interestingly, none of these contributions distinguishes resident and foreign investors.
} 
role has led the Fund to impose excessively contractionary policies (Birds and Rowlands, 2002). So far, the literature has focused on the current account and specific categories of net capital flows. A majority of studies, either regression analyses or case studies, cast doubt on the existence of any such positive effect (Ghosh et al, 2002), although a catalytic effect has been found in some circumstances. ${ }^{4}$ Mina and Martinez-Vazquez (2002), using aggregate country data, find that IMF lending reduces the countries' reliance on short-term debt flows. Eichengreen and Mody (2003) find a stronger catalytic effect for intermediate economic fundamentals. Edwards (2003) finds no catalytic effect on bond issuance. The opposite is true for Mody and Saravia (2003), who find that larger programs are associated with stronger catalysis and that a continued IMF presence in a country reinforces this effect. However, an excessively lengthy presence can be perceived as a sign of failure, discouraging capital flows. Eichengreen et al. (2005), who argue that the IMF's role as a vigilante is more likely to manifest in bond markets, find that, in high-debt countries, it is the size of assistance that attracts private capital. Focusing on the volatility of net capital flows, Broto et al. (2011) show that the larger availability of Fund resources lowers net flows' volatility. Saravia (2013) presents evidence on the relation between IMF lending and countries' private and public debt maturity choices. Saravia finds that IMF loans reduce the maturity of new debt. He argues that this is due to its senior status.

\section{Data}

Information on IMF interventions was collected from the IMF's webpage and various program reviews. While information is available from the 1950s, the data used in this paper is restricted in two dimensions. First, we do not go back beyond 1990 due to the scarcity of information on a sufficiently granular (quarterly) basis and we stop in 2008, given that the IMF changed both its Balance of Payments methodology and portfolio of crisis resolution tools in 2009. Second, we only focus on the IMF's two traditional credit lines of crisis resolution which are funded through its general resources: the IMF Stand-By Arrangement (SBA) and the IMF Extended Fund Facility (EFF). The SBA, established in 1952, is the IMF's workhorse lending instrument for emerging and advanced market countries. The SBA aims to help member countries address their shortterm balance of payments problems, emerge from crisis and restore sustainable growth. The Extended Fund Facility (EFF) focuses on helping countries overcome their medium/longer-terms balance of payments problems. This implies a longer program engagement (up to 4 years instead of 3 under the SBA) and a longer repayment period (up to 10 years instead of the 5 allowed for the SBA). After this selection, we finish with a sample of over 140 programs. The data set includes the date of the arrangement, the actual date at which the program

\footnotetext{
${ }^{4}$ Various papers have tested whether access to capital markets response to IMF lending differs with the program design (see, for example, Erce, 2012).
} 
finished (end of the arrangement), the type and size of the program. ${ }^{5}$

The capital flows data comes from the analytic presentation of the IMF's Balance of Payments Statistics Yearbooks (BOP). The IMF's BOP dataset provides detailed disaggregated country-level data, on a quarterly basis since 1970 . This dataset allows us to construct various measures of Gross Capital Flows, including by type of Flow. To understand the true catalytic effect of assistance programs into capital flows we have to be careful in defining what is being "catalyzed". In this sense, just looking at a typical measure of Net Capital Flows (i.e. changes of all liabilities - changes of all assets) could be misleading. To see this, simply imagine that the impact of international assistance programs has an asymmetric effect on the behavior of domestic resident investors and foreign investors; aggregating these, potentially opposite, effects could hide the true nature of these programs' catalyzing role. Furthermore, asymmetric effects could arise in the direction of the flows regardless of the residency of the investors or even among the different type of flows. More importantly, from a policy perspective, not all flows are the same. The negative economic effects of sudden net inflow reversals are well documented. ${ }^{6}$ Additionally, shocks to specific components of the net inflow, i.e. foreign investment reversals or domestic retrenchment could potentially lead to external crisis (Janus and Riera-Crichton, 2015). To capture this set of potential asymmetries, we use two different decompositions of the net inflow to create our gross measures of capital flows. On the one hand, we use the residence decomposition:

$$
\text { Net } \text { Inflow }_{i t}=\triangle \text { Liabilities }_{i t}-\triangle \text { Assets }_{i t} .
$$

This decomposition allows us to distinguish capital outflows by domestic agents (COD), marked by changes in foreign assets held by domestic residents, from capital inflows by foreigners (CIF), which are measured as changes in liabilities of the reporting country's residents held by foreign nationals (see Broner et al. 2013).Alternatively, given that negative or positive values on the change of assets and liabilities denote a specific direction of the capital flow, we can decompose the net inflow as:

$$
\begin{aligned}
& \text { Net } \text { Inflow }_{i t}=\text { Gross } \text { Inflows }_{i t}-\text { Gross Outflows }{ }_{i t}= \\
& =\left(\triangle \text { Liabilities }_{i t}^{+}+\triangle \text { Assets }_{i t}^{-}\right)-\left(\triangle \text { Liabilities }_{i t}^{-}+\triangle \text { Assets }_{i t}^{+}\right)
\end{aligned}
$$

where now we aggregate flows based on their direction (in/out) and not on the residency of the transaction originators. ${ }^{7}$ In other words, in this aggregation, gross inflows accumulate flows of capital invested in the country by

\footnotetext{
${ }^{5}$ The data set also includes the original (programmed) expiration date. Actual and programmed end dates may differ either due to a program extension or an early cancellation. Using these dates one could compute both the program duration on approval and actual duration. Additional information includes the volume of funds finally drawn under the program, size and date of any program augmentation and information about its precautionary character.

${ }^{6}$ See Calvo (2003) or Hutchinton and Noy (2006).

${ }^{7}$ See Janus and Riera-Crichton (2015).
} 
foreign investors $\left(\triangle\right.$ Liabilities $\left._{i t}^{+}\right)$plus the capital domestic residents repatriate $\left(\triangle\right.$ Assets $\left._{i t}^{-}\right)$, while gross outflows accumulate the purchase of foreign assets by domestic investors $\left(\triangle A\right.$ sset $\left._{i t}^{+}\right)$, plus the repatriation of capital from the domestic economy by foreign nationals $\left(\triangle\right.$ Liabilities $\left._{i t}^{-}\right)$.

Using these two definitions of the net inflow, we build nine basic series of gross capital flows: Total Gross Flows, Capital Outflows by Residents, Capital Inflows by Foreigners, Total Private Inflows, Total Private Outflows, and the four individual components of definition (1).

Finally, our dataset includes additional variables that are used as controls, either in the panel regressions and linear projections, or as instruments when implementing our instrumental variables strategy. The controls include the High Yield Index, the VIX index and the Federal Funds Rate obtained from DataStream, and the Chinn-Ito Index of capital account liberalization and nominal GDP growth from the World Economic Outlook database.

\section{Empirical Analysis}

In this section, we showcase the results of our empirical analysis on the effects of IMF financial assistance on the components of the net capital inflow. First, we report some important stylized facts from our main variables. Then, we turn to the regression analysis. We start with a simple least squares dummy variable (LSDV) estimation approach with lagged independent variables. While the lagged structure imposes some degree of causal direction in our regressions, we are well aware of the potential feedback effects and, therefore, potential endogeneity bias in our main coefficients. To address these concerns, we collect a series of instruments documented in the political science literature and use them in a panel instrumental variable (IV) approach. While a good first step to examining the effects of Fund programs on capital flows, our LSDV and panel IV estimations are unable to capture the potentially rich dynamics between these variables. To understand these dynamics better, we use the Local Projections methodology introduced by Jorda (2005) and Stock and Watson (2006) to estimate a set of efficient impulse response functions. As a final robustness check, we combine our IV analysis with the local projections methodology.

\section{Stylized Facts on IMF Lending and Gross Capital Flows}

Table 1 shows the summary statistics for IMF programs. As mentioned above we have a large number of programs (147 program onsets) but, perhaps even more remarkable, approximately 23 percent of our observations correspond to an ongoing IMF program. Countries in our sample underwent, on average, three IMF programs during our sample period. There is a large variation in the size of the programs both in absolute terms and relative to the countries quota with an average of 1.3 billion SDRs or 121 percent of the country's quota at the Fund. To complete the dynamic view of our Fund Program data, Table 2 presents a transition probability matrix. This matrix shows that those countries without 
an ongoing program have around a 3 percent chance of an onset, while those undertaking a program face around a 90 percent probability of continuation.

In the last part of the paper, we study the interaction between IMF assistance programs and different crisis types. While, by design, an IMF presence is closely related to balance of payment problems, many of the episodes studied are not associated with the standard crisis indicators (currency, banking or debt crises). This may be because the country avoided a deeper deterioration of its macroeconomic situation or because the Fund was present in a (successful) preventive role. In those cases in which the countries do descend into macroeconomic turmoil, the reaction of capital flows to a Fund program could differ significantly across the varying types of underlying crisis. In this paper, we focus on four types of crisis: currency, banking and sovereign debt from both a domestic and a foreign perspective. Our data on economic crises is based on Carmen Reinhart's variety of crises dataset. As her dataset does not cover all of our sample countries, we have also used information from S\&P, Laeven and Valencia (2013) and Broner et al. (2013). Table 3 gives us an idea of the number and distribution of assistance program onsets across our sample as well as the interaction between program onsets and economic turmoil. From this table we observe that around 56 percent of Fund program onsets are in crisis-hit countries, with the programs begun in the midst of a currency, banking, external sovereign debt and domestic sovereign debt crisis in 61, 50, 43 and 18 percent of the times, respectively. ${ }^{8}$ The table also provides information on the average number of IMF programs per country and the total number of countries with at least one onset. We have 39 countries with at least one program onset, among these, each country has an average of 3.7 onsets during the sample period.

Table 4 shows the summary statistics for the different measures of Capital Flows and explanatory variables used in the paper. We observe that Total Gross Flows (sum of the four components of equation 1) hover at around 28 percent of GDP. Most of these flows originate from the private sector (23 percent). If we split the sample purely by the direction of the flow, we observe that, in our sample, total private flows are divided into 12 percent inflows and 10 percent outflows. If we split the flows by residence of origination, we discover that the volume of CIF revolves at around 7 percent of GDP and COD at around 4.5 percent. Splitting the sample by type of flow, we observe that most of the recorded flows correspond to the category of "Other Investment" (14 percent of GDP), which is dominated by international banking transactions. Foreign Direct Investment (FDI) with 5.5 percent and Portfolio Investment with 3.6 percent follow. When looking at the four components from our net inflows decomposition, we observe that the typical flows -inflows from increases in foreign liabilities and outflows from increases in foreign assets- are the largest components with 10 and 7.5 percent of GDP, respectively. Investment reversals (outflows from decreases in foreign liabilities) and domestic retrenchment (inflows from decreases in foreign assets) follow with around 3 percent of GDP

\footnotetext{
${ }^{8}$ Nothing precludes an IMF program from being put in place against the backdrop of a twin or triple crisis.
} 
each.

Figure 1 shows the evolution of gross flows against the backdrop of the number of programs in effect. Decomposing Total Gross flows into Private and Public Gross Flows, we identify two distinct waves of financial integration. The first wave runs from the end of the EMS crisis in 1993 to the beginning of the Asian Crises in 1997. After the Asian and Russian Crises (1997-98), private gross flows slowly declined until the end of the Argentinean crisis in 2002. The second wave arrives in the latter part of the so-called "Great Moderation" (2004-08). During this period, total private gross flows in our sample averaged 30 percent of GDP. At the same time, the number of ongoing programs declined from an average of around 12 to 2. The series of Official Gross Flows shows an interesting break in its volatility around the time of the Asian crises. Before the crises, high levels of volatility, reaching peaks above 10 percent of GDP, characterized the official flows. After 1997, the series remained subdued at around 3 percent of GDP. Another interesting decomposition of Gross Flows, shown in figure 1, focuses on gross flows by residence and by direction of flow. Looking at the inflow/outflow decomposition by residence we observe the collapse of both measures, but especially inflows, during episodes of external turmoil. This, of course, follows on the footsteps of the sudden stops literature. On the other hand, looking just at the direction of the flow, we observe large surges in outflows and, to a lesser degree, inflows driven by foreign investment reversals and domestic retrenchment during crises.

\section{Least Squares Dummy Variables Estimation}

In our basic specification, we use the following simple LSDV estimation:

$$
Y_{i t}=\alpha_{i}+\delta_{t}+\sum_{n=1}^{4} \theta_{n} I M F_{i t-n}+\beta X_{i t-1}+\mu_{i t},
$$

where $Y_{i t}$ represents the different components of the net inflow of country it at time t, $I M F_{i t}$ is a dummy indicator signaling whether country i signed an IMF program at time t, and $X_{i t}$ is a vector of controls that include four lags of GDP growth, the HY Index, the Fed Funds rate, the Chinn-Ito Index of capital openness, the VIX index, and a crisis indicator taking value one whenever the country is in a crisis. Our regressions also include country and time fixed-effects and a time trend.

Results from this simple specification are displayed in Table 5. In terms of the coefficients of the controls, there are no surprises. As in Alberola et al. (forthcoming), economic growth helps increase foreign inflows but is not so clearly related to outflows. Good High-Yield performance promotes both inflows and outflows, increasing total gross flows. Instead, financial turmoil slows foreign inflows significantly. Capital openness seems to encourage total gross flows and financial volatility (VIX) deters domestic outflows.

Regarding the effect of IMF programs, to help our analysis, we report the sum of all lagged coefficients of the IMF onset dummy. We measure significance 
with a Wald Test of the null of the sum of the four coefficients being zero. From the table, we can observe that, related to the previous literature, program onsets seem to have no catalytic effect on net inflows, pushing countries into larger current account surplus and having no effect on total private gross flows. A more complete story surfaces when looking at the decomposition of the net inflow by direction of flows and by origination of those flows. The last two columns of Table 5 show the reaction to the onset of a Fund program by foreign inflows and resident outflows. From these two columns it becomes clear that the "no effect" on total private flows results from a weighted average of two important and opposite forces. On the one hand, the program onset seems to have an "anti-catalytic" effect on inflows from foreigners, prompting a relatively large decrease of those inflows in the year following the onset. On the other, it seems to exercise a catalytic effect of similar size on outflows from residents. In other words, the Fund program onset prevents to some degree domestic capital flight. The size and timing of these effects, however, differ. While after four quarters the accumulated decrease in inflows from foreigners and outflows from residents are similar at around $50 \%$ of GDP, the bulk of the inflow effect occurs in the first quarter following the program's establishment and the bulk of the outflow effect with a lag of two quarters. We explore these interesting dynamics in the sections below.

\section{Panel Instrumental Variables Estimation}

Eichengreen and Mody (2003) argue that, when trying to understand the effect of IMF programs on macroeconomic outcomes, it is necessary to control for the fact that selection into such programs is non-random, as this could bias the estimated coefficients. In this section, we apply an instrumental variables approach to tackle this problem. As described below, our choice of instruments is guided by a significant body of research that has focused on understanding the political and geo-strategic determinants of IMF lending. As noted by Edwards and Santaella (1993), Barro and Lee (2005) and Saravia (2013), the literature has uncovered a set of geo-political and institutional determinants of IMF lending, which can be used to address endogeneity concerns. More specifically, we base our identification on four different sets of political factors: internal IMF politics, borrowing country's politics, geo-politics and official sector politics.

As regards the role of internal IMF politics, Barro and Lee (2005) and Saravia (2011) argue that a country's quota at the IMF is also a significant determinant of IMF financial support. ${ }^{9}$ Country quotas can serve as an instrument to the extent that they indicate the country's political power within the institution. In turn, we model the borrowing country's political factors as follows. Vreeland (2006) observes that countries where the political system has more veto power are more likely to have IMF programs and that countries are less likely to sign

\footnotetext{
${ }^{9}$ Relatedly, Dreher and Vaubel (2004) and Copelovich (2004) include the total amount of resources available to the Fund as a determinant of IMF lending. Also overall resources and fresh injections of resources can be used as instruments as they may reflect IMF-bureaucrats incentives to lend (Dreher and Sturm, 2006).
} 
IMF programs when elections are coming up soon. Relatedly, Dreher (2002) shows that IMF programs are more likely to go off-track ahead of elections. In turn, Edwards and Santaella (1993) find that dictatorial regimes are less likely to engage with the IMF. They rationalize such results as follows. An important role of international organizations is to do national governments' "dirty work." By involving multinational bodies in the decision-making process, local politicians can shield themselves from the political fallout associated with unpopular policies. This implies that governments with a more unstable political base, and thus likely to suffer more severely from unpopular policies, will recur more frequently to the IMF. A second implication of this public choice view is that, other things being equal, countries with dictatorial regimes will have a smaller incentive to request IMF assistance. This is because dictatorial regimes, in general, can withstand unpopular adjustment programs without suffering serious political consequences. In turn, Tacker (2000), Barro and Lee (2005) and Dreher and Sturm (2006) provide us with geo-political instruments. They argue that political proximity, as measured by the various countries' voting alignment with the US (and other advanced economies) at the United Nations and other international fora, helps explain IMF lending. ${ }^{10}$ Finally, we use two variables associated with the politics of the official sector. First, we use the signing of an agreement with the Paris Club, which automatically requires the signing in turn of an IMF program. Papi et al.'s (2014) analysis of the effect of IMF lending on banking crises successfully uses flows of development assistance (ODA flows) into the economy as an instrument for IMF lending. We follow them and include that variable in our estimations.

With this identification strategy in mind, we estimate the following model of the effects of IMF programs on gross capital flows:

$$
\begin{gathered}
I M F_{i t}=\alpha_{i}+\delta_{t}+\varphi X_{i t-1}+\gamma Z_{i t-1}+\varepsilon_{i t}, \\
Y_{i t}=\alpha_{i}+\delta_{t}+\sum_{n=1}^{4} \theta_{n} \widehat{I M F_{i t-n}}+\beta X_{i t-1}+\mu_{i t} .
\end{gathered}
$$

Equation (2) models the presence of the International Monetary Fund. Equation (3) models the determinants of gross flows. Equation (2) is estimated using a lineal panel data model. $Y_{i t}$ represents the different types of capital flows used in the analysis. $X_{i t-1}$ covers a set of lagged controls including, as before, output growth, foreign interest rates, capital control measures, crisis dummies and foreign financial volatility measures. In turn, $Z_{i t-1}$ contains the political and geo-strategic factors used to instrument the IMF's presence. The variable $\widehat{I M F} \widehat{T}_{i t-n}$ defines the estimated likelihood of signing a program with the Fund obtained from equation (2). Our regressions include country fixed effects, time effects and a time trend in an effort to capture the increases in global financial integration. Finally, we use HEC errors clustered by country.

\footnotetext{
${ }^{10} \mathrm{http}$ ///www.uni-heidelberg.de/fakultaeten/wiso/awi/professuren/intwipol/datasets.html.
} 
We include in $Z_{i t-1}$ all of the instruments discussed above. The first-step results are presented in Table 6a. Most of our instruments are highly significant. Even more importantly, they display the expected signs. Thus, countries with more influence (via IMF quota, their presence on the UN Security Council or their alignment with the US at UN voting) are more likely to be granted assistance. Also as expected, dictatorial regimes are less likely to ask for support than democracies. And, again as expected, countries are less likely to request assistance during and prior to elections. Finally, higher ODA assistance and negotiations with the Paris Club function as robust predictors of countries accessing IMF resources.

In the second step, we regress our various gross capital flows measures against the instrumented lag of the IMF indicator and our set of exogenous determinants of the gross flows used in the previous specification. ${ }^{11}$ Table $6 \mathrm{~b}$ shows the results for the gross flows equation (second step). As before, we provide the sum of the coefficients of the four lags on every IMF lending agreement. Our IV analysis corroborates the main set of results found in the LSDV specification. First, when we focus on the direction of the flows, we find that IMF programs are accompanied by a greater reduction in the volume of private capital flowing in (be it of resident or foreign origin). In this dimension, one could argue that the IMF is not capable of catalyzing the entry of capital into the intervened economy. There is, however, also no evidence of significantly higher capital outflows. This means that, at least, the signing of an IMF program does not accelerate the exit of capital already invested in the economy. Second, from a residence perspective (last two columns), we again obtain very stark and interesting results. While the IMF is able to catalyze domestic capital flows (reducing the domestic capital drain), it does not seem to be able to reduce the capital flight by foreigners. In fact, if anything, IMF programs apparently trigger further foreign capital flight. It is important to note that when using our IV estimation, we step out of the original diff-in-diff framework making it difficult to relate the estimated coefficients to the relative size of the impact on capital flows. ${ }^{12}$

Table 7, which presents our estimates of domestic and foreign flows broken down by those entering and those exiting the economy, further reinforces the idea that the IMF significantly affects the behavior of domestic investors. The estimated coefficients show that resident investors are more likely to repatriate their foreign assets, compensating somehow for the reduced entry of fresh foreign capital. Finally, Table 8 repeats the analysis but this time using the categorization of the capital flows. Thus, we distinguish flows of entry and exit for FDI, portfolio investment and other investment. Although we also find a significant negative effect on the inflow of foreign FDI, the results show that a program's effects are stronger on other investment categories. As this indicates that the results obtained when looking at broader gross flows measures are largely driven by domestic banks' flows, we conclude that IMF catalysis appears to work best

\footnotetext{
${ }^{11}$ Since the results from our exogenous controls are very similar those found in Table 5, we decided not to include them. A complete set of results can be obtained by request.

${ }^{12}$ Our estimated IMF program variable is no longer a 0-1 dummy.
} 
vis-à-vis domestic banks.

\section{Dynamic effects}

So far, we have not focused on the rich dynamic responses of capital flows to the inception of an assistance program. In this section, we study such dynamics by presenting a set of representative cumulative impulse response functions using the local projections methodology.

In our cumulative impulse response function estimation strategy, we follow Jorda (2005), Stock and Watson (2007), and others in the use of linear "local projections" (LP) for the construction of our impulse response functions (IRFs). This methodology allows us to directly project the behavioral reaction of gross private capital flows to the signing of an IMF financial assistance program by computing estimates of the h-step ahead cumulative average treatment effect on the gross flows variables. ${ }^{13}$ This methodology provides a flexible alternative to VAR approaches. As described by Jorda (2005), linear projections can be estimated by simple single regression techniques (LSDV in our case) and they are more robust to misspecification errors. While widely used in the literature, as explained in Ramey (2014), this method does not consistently dominate the standard Structural VAR method for calculating impulse responses of endogenous variables with contemporaneous effects. Since local projections do not impose any restrictions linking the impulse responses at $\mathrm{h}$ and $\mathrm{h}+1$, estimates can display erratic behavior due to the loss of efficiency. Additionally, as the horizon increases, one loses observations from the end of the sample. Finally, the impulse responses sometimes display oscillations at longer horizons. Comparing Jorda to a standard SVAR and a dynamic simulation, Ramey (2012) finds that the results are qualitatively similar for the first 16 quarters. For longer horizons, however, the Jorda method tends to produce statistically significant oscillations not observed in the other two methods. Since, in this study, we are interested in the short- and medium-horizon effects of fund programs on Gross Flows we can safely disregard these drawbacks.

In our basic linear specification, each response of changes in capital flows to contemporaneous onset of financial assistance programs at horizon $\mathrm{h}$ is obtained from the following equation:

$$
\begin{aligned}
\triangle Y_{i, t+h}=\alpha_{i, h}+\beta_{h} I M F_{i, t}+\Psi_{h}(L) I M F_{i, t-1} & +\Phi_{h}(L) \triangle Y_{i, t-1}+ \\
& +\Upsilon_{h} \triangle X_{i, t-1}+\sigma_{t, h}+\mu_{i, t, h}
\end{aligned}
$$

where $\triangle Y_{i, t+h}=Y_{i, t+h}-Y_{i, t+h-1}$ for $h \geq 0$, and $\triangle Y_{i, t+h}$ represents the accumulated capital flow measure over GDP at time $t+h$. The lag polynomials $\Psi_{h}(L)$ and $\Phi_{h}(L)$ represent four lags. $I M F_{i, t}$ represents the dummy for the signing of an IMF program and $X_{i, t-1}$ covers the same set of lagged controls

\footnotetext{
${ }^{13}$ Local projections are, in practice, regression-adjusted difference-in-difference estimates that collapse the time series information in a pre and a post period for each step ahead.
} 
used in the previous sections. Finally, we include a full set of country and year dummies. Every equation, for each $h$, is estimated using a standard LSDV approach. We use robust Driscoll and Kraay (1998) standard errors to correct for potential heteroscedasticity, autocorrelation in the lags and error correlation across panels.

Figures 2 to 8 give us the projected reaction of different flows to the onset of an IMF program. Looking at figure 2, we observe a steady increase in total gross flows over time after the onset of a program. This increase is driven entirely by official gross flows since the aggregated private flows stay flat and even start decreasing after a year (although the coefficient remains statistically insignificant.) As before, interesting results appear after decomposing the gross private flows into inflows and outflows. As we can see from figure 3, the first asymmetry between foreign inflow (CIF) and domestic outflow (COD) responses is represented by CIF's faster reaction to the program's onset; we observe a significant drop in CIF on impact, around 6 percent of GDP. Meanwhile, COD only starts to react 2 quarters after the program signing, with a similar size drop. A second asymmetry is observed on the size and standard deviation. CIF peaks close to an accumulated drop of 10 percent of GDP but it displays larger standard errors. COD peaks at an accumulated drop of around 15 percent of GDP with tighter errors. This lends credence to our previous narrative in a dynamic setting: we observe that the presence of the fund has a significant catalyzing effect on domestic outflows in the medium run while it also seems to significantly discourage foreign inflows only in the very short run. Looking at the decomposition of private flows by their direction, regardless of the residence of the originators, gives us a more muted version of the same story. Figure 4 shows how inflows react strongly and immediately while outflows seem to decrease mildly only after six quarters. The fact that we found relatively less robust results when looking at flows by direction is another indication that the presence of the Fund affects the decisions of domestic and foreign agents differently. This is shown in more detail in figure 5, where we decompose the Net Inflow into four components by direction and origin of flow. Looking at the four panels of figure 5, we see that while the presence of the fund deters new inflows from foreigners in the short run and, of less statistical significance, in the medium run (panel A), it does not lead to capital flight (panel D). If anything, capital withdrawals from foreigners seem to be reduced in the medium run (albeit not in a statistically significant way). On the other hand, the presence of the fund not only seems to help prevent domestic residents from sending their capital abroad (panel C), it also seems to lead to domestic retrenchment in the medium run (panel B).

Figures 6 to 8 look at the IRFs for each type of flow. Interestingly, the pattern described for aggregate flows seems to be driven by the "other investment" component. With cross-country bank loans representing the bulk of this type of flows, we seem to be looking at a "banking story". Figure 6 shows the reaction of FDI, CIF and COD to the onset of an IMF program. Given the long-term nature of these flows, it is not surprising that the point estimates of the IRFs 
remain relatively stable after the shock. In any case, we do observe an increase in outflows in the medium run peaking at around 2 percent of GDP after 5 quarters and a statistically significant accumulated decrease of FDI inflows at around 3 percent of GDP after 2 quarters.

Figure 7 turns to the reaction of Portfolio (debt and equity) flows. Not surprisingly given the short-term nature of these flows, we observe larger variations among the point estimates of these IRFs. Interestingly, the IMF seems to be successful at reducing significantly the amount of COD in the first 4 quarters with an accumulated reduction peaking close to 4 percent of GDP. Again, the IMF presence seemed ineffective in promoting portfolio CIF, although we do observe an increase in these flows after 2 years. Finally, figure 8 shows the reaction of "Other Investment Flows" (OI). "Other Investment" flows are composed of international loans, trade credits, currency and other flows. The bulk of these flows lay accumulated in the international loans category. Figure 8 shows that the reaction of both OI CIF and OI COD is an order of magnitude larger than what we observed with FDI and PI. In this case, the pattern of both IRFs mimics the general pattern described in the beginning of this section. CIF decrease around 5 percent of GDP on impact and peak after five quarters at around 12 percent of GDP. COD take 2 quarters to react but then, after just six quarters, peak at an accumulated decrease of around 16 percent of GDP. While the reduction of both CIF and COD is statistically significant at $95 \%$ confidence level, errors are smaller for COD.

Next, as a robustness check given the potential endogeneity issue described in the previous section, we follow Jorda et al. (2014) and use an instrumental variables approach in our local projection regressions:

$$
\begin{aligned}
\triangle Y_{i, t+h}=\alpha_{i, h}+\beta_{h} I M F_{i, t} & +\Psi_{h}(L) \widehat{I M F_{i, t-1}}+ \\
& +\Phi_{h}(L) \triangle Y_{i, t-1}+\Upsilon_{h} \triangle X_{i, t-1}+\sigma_{t, h}+\mu_{i, t, h}
\end{aligned}
$$

where $I \widehat{M F}{ }_{i, t}$ represents the signing of an IMF program, instrumented using the variables introduced in the previous section.

Figures 9 and 10 show the results of these Instrumented Local Projections. In figure 9, we report the IRFs for foreign inflows (CIF) and resident outflows $(\mathrm{COD})$ to a one standard deviation increase in the estimated probability of a Fund program onset. The results are even stronger than those using the program onset dummy directly. The same can be said when we decompose the capital flows by direction in figure $10 .^{14}$

As mentioned before, using an IV methodology pushes us away from the original diff-in-diff framework, making it difficult to relate the estimated coefficients with the relative size of the response. Nevertheless, in this configuration, our

\footnotetext{
${ }^{14}$ We performed a battery of (unreported) tests, including the Kleibergen-Paap under identification and weak identification tests and the Hansen's over identification test, to assess the validity of our instruments. All of them supported our identification strategy.
} 
instrumented IMF variable proxies for the public expectations on IMF action. Thus, we read figures 9 and 10 as the capital flows reaction to rising expectations of a Fund program onset. In fact, given that expectations seem an important driver of capital flows, to make sure that our previous results are not biased by reactions to expectations, we upgrade our previous local projection specification including a lagged term of our instrumented measure of IMF program onset. Comfortingly, the results, displayed in Figure 11, show no significant changes in our original results.

\section{Dynamic effects and underlying vulnerabilities}

As mentioned above, an IMF presence could lead to different effects depending on the underlying macroeconomic circumstances of the country requesting the program. In this section we study this possibility. In figures 12 to 18 we capture these differences showing the IRFs of the effects of programs under a set of different economic crises and we compare them to a baseline IRF under no crisis. To calculate these non-linear effects we upgrade our original local projection estimation to include an interaction term with each type of crisis. Thus, our new estimation strategy is based on the following equation:

$$
\begin{aligned}
\triangle Y_{i, t+h}=\alpha_{i, h}+\beta_{1, h} D_{i, t} & +\beta_{2, h}\left(I M F_{i, t} \cdot D_{i, t}\right)+\Psi_{h}(L) I M F_{i, t-1}+ \\
& +\Phi_{h}(L) \triangle Y_{i, t-1}+\Upsilon_{h} \triangle X_{i, t-1}+\sigma_{t, h}+\mu_{i, t, h}
\end{aligned}
$$

where $D_{i, t}$ is a crisis dummy and $I M F_{i, t}$ represents our IMF dummy. We test the effects of program onsets in four types of economic turmoil: currency crises, banking crises and domestic and external sovereign debt crises, and also using a dummy capturing any type of crisis. We build the baseline IRF from the coefficients $\beta_{1, h}$ (where we assume $I M F_{i, t}=0$ ) and we compare these results to the sum of $\beta_{1, h}+\beta_{2, h}$ (equivalent to assuming $I M F_{i, t}=1$ ). ${ }^{15}$ Finally, we test the statistical significance of the differences between the effects under crisis and without crisis. This test is equivalent to test for $\beta_{2, h}=0$. We include a yellow marker in the $y$-axis if the difference is significant at a $90 \%$ confidence level.

Figures 12 to 16 focus on the response of COD. Figure 12 shows the reaction of COD to a program onset under the presence of any type of crisis. As in the baseline specification, the effects on outflows of a program onset during a crisis do not appear until the second quarter after the shock. Interestingly, while the final accumulated response is similar during and outside crisis episodes, the medium-run response is not. During crisis, the reduction in COD is much sharper after only 2 quarters, dropping beyond an accumulated 10 percent of GDP by the third quarter and peaking at 25 percent in the fifth quarter.

When we break down the analyses by type of crises, we observe a range of interesting asymmetries. As shown in figure 13, the effects of program onsets on COD during currency crises are very similar to those of figure 12. The

${ }^{15}$ In other words, we analyze the effect of IMF lending under the baseline of turmoil. 
IRF during these periods lead to an accumulated drop in COD of around 22 percent of GDP after five quarters. During banking crises (figure 14), we observe statistically lower point estimates than the baseline only for the second and third quarter with a maximum drop in COF close to 40 percent after 5 quarters. Responses during domestic sovereign defaults, collected in figure 15 , show a very different story. During these types of events, fund intervention seems to lead towards a consistently larger catalyzing effect on COD compare to the baseline model. Our estimates show an ever-decreasing point estimates for COD that reaches a whopping 100 percent of GDP after 7 quarters. Finally, the effects on COD of IMF programs during sovereign external crises seem significantly larger than the baseline model in the medium run (from 2 to 6 quarters out) but collapse to similar point estimates afterwards. As shown in figure 16, the COD responses during these episodes peak at an accumulated drop of 38 percent of GDP after 3 quarters.

The IRF of CIFs draw a very interesting set of results as well. While, in general, the presence of the fund lowers CIFs during crises beyond the estimates found in the baseline (under crises) estimation, in contrast to COD, these differences show large and significant effects during currency and banking crisis and smaller or insignificant differences during domestic and external sovereign crises. To display these effects we turn to figures 17 to 21 .

In figure 17, we observe that the response of CIF to program onsets during any type of crisis is always larger than the baseline estimates. Once the program is in place, CIF drops by 10 percent of GDP on impact and the response peaks after 8 quarters at around 58 percent of GDP. In contrast, the baseline estimates are very close to zero in the short run and peak around 40 percent of GDP in the long run. In any case, the differences between these two responses are only statistically significant at a $90 \%$ confidence level during the first 3 quarters. When we turn to currency crises in figure 18, the differences in CIF responses to program onsets against the baseline estimates are very similar to the ones described for any crisis. During these crises, CIF drop beyond 20 percent of GDP immediately after the program is put in place and the effect peaks at 84 percent of GDP after 8 quarters. As shown in figure 19, the CIF responses during banking crises are significantly lower than those of the baseline estimation during the first 5 quarters after the program is put in place. In this case, the drop in CIF peaks at 60 percent after 5 quarters. Finally, figures 20 and 21 show that, as in the baseline, the presence of the fund during sovereign crises (domestic or external) does not lead to statistically significant moves in CIF.

\section{Conclusions}

In this paper, we study the catalytic effect of IMF lending from a gross flows perspective. Our results show significant differences in how resident and foreign investors react to IMF programs. The asymmetric effects uncovered in this paper offer new insights into when and how the Fund's lending can have a catalytic effect on the net flow of capital. While the IMF does not appear able 
to catalyze foreign capital, there is substantial evidence that it does affect the behavior of resident investors. Remarkably, the change comes from both a more muted domestic capital flight and an increased repatriation of residents' savings abroad. We also find that most of the catalytic effect relates to banking flows. Thus, we posit that IMF catalysis is "a banking story".

\section{References}

[1] Barro, R. and J.W. Lee (2005), "IMF programs: Who is chosen and what are the effects?", Journal of Monetary Economics, vol. 52.

[2] Birds G., and D. Rowlands (2002), "Do IMF Programmes Have a Catalytic Effect on Other International Capital Flows?, Oxford Development Studies, Vol. 30, No. 3 .

[3] Broner, F., Didier, T., Erce, A., and S. Schmuckler (2013), "Gross Capital Flows: Dynamics and Crises", Journal of Monetary Economics, Volume 60, Issue 1.

[4] Broto, C., Diaz-Cassou, J. and A. Erce (2011), "Measuring and explaining the volatility of capital flows towards emerging countries", Journal of Banking and Finance - Volume 35 (8).

[5] Calvo, G. (2003), "Explaining Sudden Stops, Growth Collapse and BOP Crises: The Case of Distortionary Output Taxes", NBER Working Papers 9864 .

[6] Copelovich, M. (2004), "Private Debt Composition and the Political Economy of IMF Lending", Mimeo.

[7] Corsetti, G., Guimaraes, B. and N. Roubini (2006), International lending of last resort and moral hazard: A model of IMF's catalytic finance, Journal of Monetary Economics, vol. 53(3).

[8] Cottarelli, C. and C. Giannini (2002), "Hostages, bed fellows or perfect strangers: Global Capital Markets and the catalytic effect of IMF Crisis Lending", IMF Working Paper No. 02/193.

[9] De Resende, C. (2007), "IMF-Supported Adjustment Programs: Welfare Implications and the Catalytic Effect". Bank of Canada, Working Paper No. 2007-22.

[10] Diaz-Cassou, J. and A. Garcia-Herrero (2006), "What Kind of Flows Does the IMF Catalyze and When?". Bank of Spain Working Paper, No. 0617.

[11] Dreher, A. (2002)," The Influence of Elections on IMF program Interruptions", mimeo. 
[12] Dreher, A., and R. Vaubel (2004), "Do IMF and IBRD cause moral hazard and political business cycles? Evidence from panel data", Open Economies Review 15(1). 18

[13] Dreher, A. and J. Sturm (2006), "Do IMF and World Bank Influence Voting in the UN General Assembly?", KOF Working Paper 137.

[14] Edwards, M., and J.A. Santaella (1993), "Devaluation Controversies in the Developing Countries: Lessons from the Bretton Woods Era", in A Retrospective on the Bretton Woods System: Lessons for International Monetary Reform (edited by M.D. Bordo and B. Eichengreen)

[15] Edwards, M. (2003), "Signalling credibility? The IMF and catalytic finance", Mimeo.

[16] Eichengreen, B. and A. Mody (2003), "Bail Ins, Bailouts, and Borrowing Costs, Journal of Econometrics, Vol. 36.

[17] Eichengreen, B., Kletzer and A. Mody (2005), "The IMF in a World of Private Capital Markets", IMF Working Paper 05/84.

[18] Erce, A. (2012), "Does the IMF's official support affect sovereign bond maturities?", Bank of Spain Working Paper 1231.

[19] Forbes, K and F. Warnock (2012), "Capital Flow Waves: Surges, Stops, Flight and Retrenchment", Journal of International Economics, Vol. 88, Issue 2.

[20] Ghosh, A., Lane, T., Schultze, G., Bulir, M., Hasmann, J. and A. Mourmouras (2002), "IMF Supported Programs in Capital Account Crises", IMF Occasional Paper No. 210.

[21] Hutchison, M. and I. Noy 2006. Sudden Stops and the Mexican Wave: Currency Crises, Capital Flow Reversals and Output Loss in Emerging Markets. Journal of Development Economics 79, 1, 225-48.

[22] IMF (2013), Sovereign Debt Restructuring - Recent Developments and Implications for the Fund's Legal and Policy Framework, International Monetary Fund, Policy Document.

[23] Janus, T., and D. Riera-Crichton (2015), "International gross capital flows: a new measure and application to a global panel", Journal of Policy Modelling, forthcoming.

[24] Jeanne, O., Ostry, J. and J. Zettelmeyer (2008), A Theory of International Crisis Lending and IMF Conditionality, CEPR Discussion Papers 7022.

[25] Jordà, O. (2005), "Estimation and Inference of Impulse Responses by Local Projections." American Economic Review, 95(1). 
[26] Jordà, O., Moritz Schularick and Alan Taylor (2014), "Betting the House", Forthcoming in NBER International Seminar on Macroeconomics 2014, Clarida, Frankel, Giavazzi, and Rey

[27] Laeven, L., and F. Valencia (2013), "Systemic Banking Crises Database", IMF Economic Review, forthcoming.

[28] Mina, W. and J. Martinez-Vazquez (2002), "IMF Lending, Maturity of International Debt and Moral Hazard". Georgia State University Working Paper, No. 03-0119

[29] Mody, A., and D. Saravia (2003) "Catalyzing Private Capital Flows: Do IMF-Supported Programs Work as Commitment Devices?", IMF Working Paper 03/100.

[30] Morris, S., and H. Shin (2006), "Catalytic Finance: When Does It Work?", Journal of International Economics, Volume 70.

[31] Papi, L., Presbitero, A., and A. Zazzaro (2015), "IMF Lending and Banking Crises", IMF WP 15/19.

[32] Peñalver, A. (2004), "How can the IMF catalyse private capital flows? A model". Bank of England, Working Paper No. 215.

[33] Saravia, D. (2013), "Vulnerability, Crisis and Debt Management: Do IMF Interventions Increase reliance on short term debt?", International Finance, Volume 16, Issue 3.

[34] Thacker, S. (2000), "The high politics of IMF lending". World Politics, 52.

[35] Vreeland (2006), "IMF program compliance: Aggregate index versus policy specific research strategies", Review of International Organisations 1: 359378.

[36] Zwart, S. (2007), "The Mixed Blessing of IMF Intervention: Signalling versus Liquidity Support". Journal of Financial Stability, 3(2). 


\section{APPENDIX}

Graph 1: Gross flows and the IMF in Uruguay (2002) and Turkey (2005)

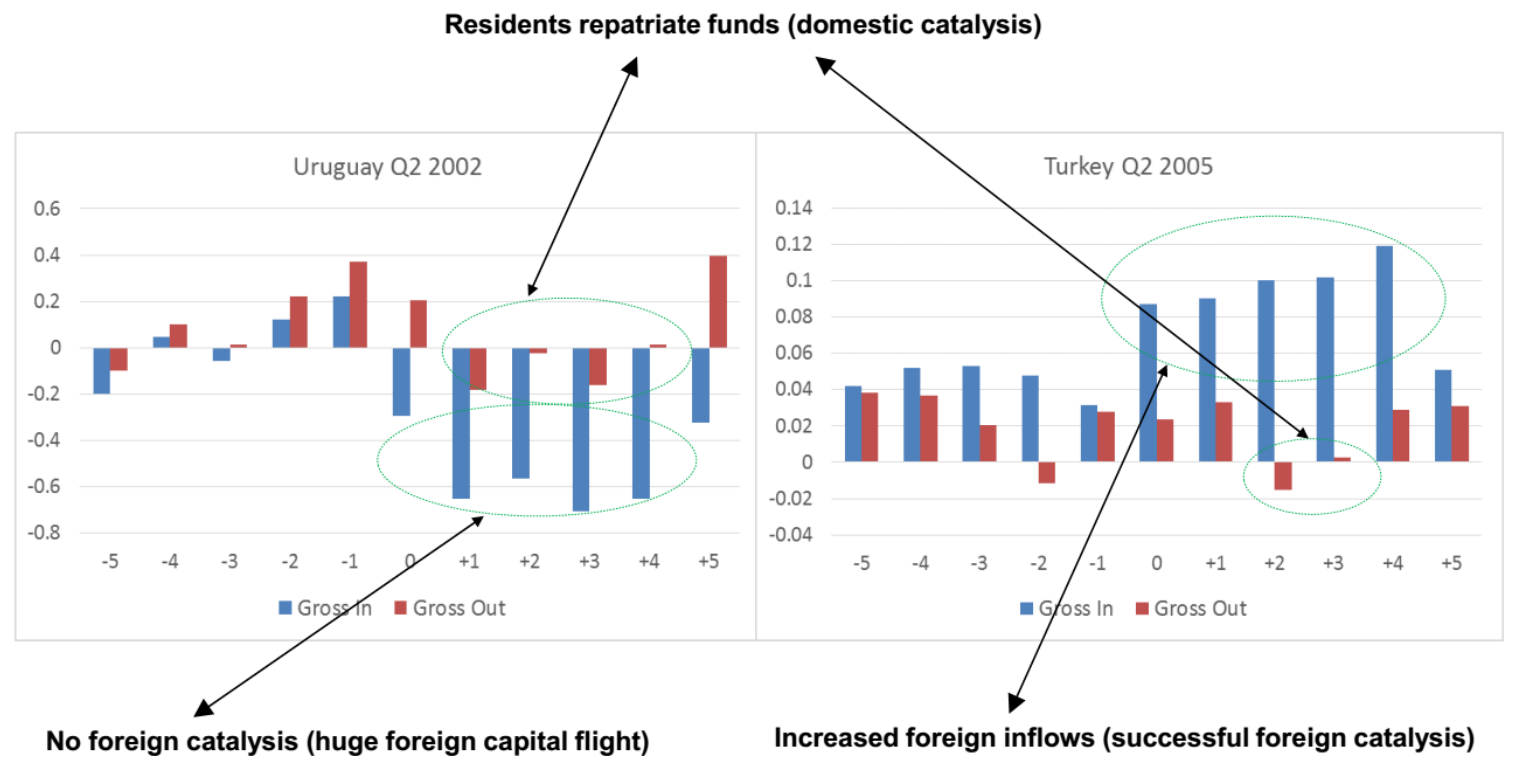

Table 1: IMF Program Summary Stats

\begin{tabular}{lccccc}
\hline Variable & Observations & Mean & Std. Dev & Min & Max \\
\hline IMF Ongoing Dummy & 4332 & 0.231 & 0.421 & 0 & 1 \\
IMF Program Size (SDR Mill) & 147 & 1318.1 & 3229.9 & 11.6 & 22821.1 \\
IMF Program Size (Rel Quota) & 147 & 121.7 & 223.8 & 15 & 1938.5 \\
IMF Program Duration (Months) & 147 & 20.6 & 10.2 & 5 & 49 \\
\hline
\end{tabular}

Table 2: Transition probability Matrix for Ongoing Fund Programs

\begin{tabular}{r|r|r|r|} 
Origin/End & \multicolumn{1}{c}{0} & \multicolumn{1}{c}{1} & \multicolumn{1}{c}{ Total } \\
\cline { 2 - 4 } 0 & 96.79 & 3.21 & 100 \\
\cline { 2 - 4 } 1 & 10.71 & 89.29 & 100 \\
\cline { 2 - 4 } Total & 76.68 & 23.32 & 100 \\
\cline { 2 - 4 } & &
\end{tabular}


Table 3: IMF programs and economic crises

\begin{tabular}{lccc}
\hline & Total Onsets & Onsets per Country & Countries with Onsets \\
\hline IMF Onset Total & 147 & 3.77 & 39 \\
IMF Onset during All Crisis & 83 & 2.59 & 32 \\
IMF Onset during Currency Crisis & 51 & 1.89 & 27 \\
IMF Onset during Banking Crisis & 41 & 1.78 & 23 \\
IMF Onset during Sovereign Dom. Crisis & 15 & 1.67 & 9 \\
IMF Onset during Sovereign External Crisis & 36 & 2.25 & 16 \\
\hline
\end{tabular}

Table 4: Gross capital flows and control variables. Summary Statistics

\begin{tabular}{lccccc}
\hline Variable & Observations & Mean & Std. Dev. & Min & Max \\
\hline Total Gross Flows & 2574 & 0.28 & 0.28 & 0.013 & 2.795 \\
Private Gross Flows over GDP & 2574 & 0.231 & 0.261 & 0 & 2.54 \\
Official Gross Flows over GDP & 2574 & 0.047 & 0.093 & 0 & 2.661 \\
Inflows from Foreigners (CIF) & 2574 & 0.069 & 0.107 & -0.534 & 0.954 \\
Outflows from Residents (COD) & 2574 & 0.045 & 0.171 & -2.038 & 2.537 \\
Gross Inflows (By Flow direction) & 2574 & 0.127 & 0.135 & 0 & 2.065 \\
Gross Outflows (By flow direction) & 2574 & 0.104 & 0.172 & 0 & 2.54 \\
FDI flows over GDP & 2574 & 0.054 & 0.085 & 0 & 1.787 \\
Portfolio Investment flows over GDP & 2574 & 0.036 & 0.076 & 0 & 1.606 \\
Other Investment flows over GDP & 2574 & 0.139 & 0.178 & 0 & 1.969 \\
Private Outflows from Liabilities & 2574 & 0.028 & 0.048 & 0 & 0.626 \\
Private Inflows from Liabilities & 2574 & 0.098 & 0.103 & 0 & 1.056 \\
Private Outflows from Assets & 2574 & 0.075 & 0.164 & 0 & 2.537 \\
Private Inflows from Assets & 2574 & 0.029 & 0.078 & 0 & 2.064 \\
Federal Reserve Funds Rate & 2574 & 4.105 & 1.951 & 0.14 & 8.32 \\
Real Output Growth (Quarter to Quarter) & 2514 & 0.076 & 0.121 & -1.633 & 0.34 \\
High Yield Index & 2574 & 446.932 & 153.475 & 131.58 & 705.29 \\
Capital Openness Index & 0.506 & 0.336 & 0 & 1 \\
VIX & 20.236 & 7.297 & 11.19 & 51.723 \\
\hline & & & & & \\
\hline
\end{tabular}


Figure 1
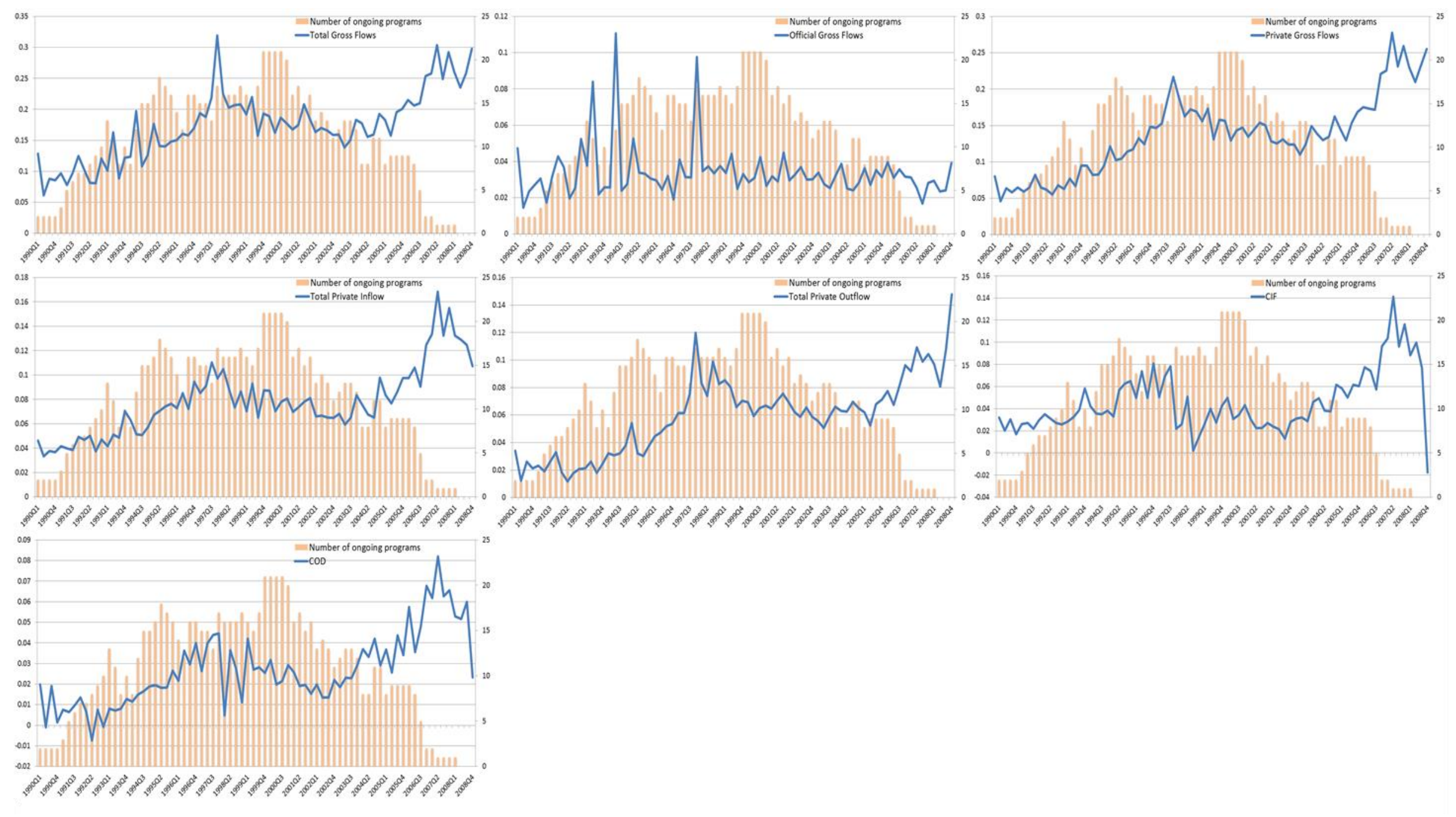
Table 5: IMF ONSETS ON CAPITAL FLOWS. LSDV ESTIMATION

\begin{tabular}{|c|c|c|c|c|c|c|c|}
\hline VARIABLES & CU & TGF & PGF & $\begin{array}{c}\text { GROSS } \\
\text { INFLOWS }\end{array}$ & $\begin{array}{c}\text { GROSS } \\
\text { OUTFLOWS }\end{array}$ & $\begin{array}{l}\text { FOREIGNERS } \\
\text { INFLOWS }\end{array}$ & $\begin{array}{l}\text { RESIDENTS } \\
\text { OUTFLOWS }\end{array}$ \\
\hline \multirow[t]{2}{*}{ IMF Onset (t-1) } & 0.2890 & -0.0146 & -0.1670 & -0.2193 & -0.0757 & -0.1829 & -0.0602 \\
\hline & {$[0.112]^{* *}$} & [0.098] & {$[0.067]^{* *}$} & {$[0.078]^{* * *}$} & {$[0.089]$} & {$[0.091]^{* *}$} & {$[0.086]$} \\
\hline \multirow[t]{2}{*}{ IMF Onset (t-2) } & 0.2527 & 0.1625 & 0.0807 & 0.0460 & -0.0064 & -0.0754 & -0.2264 \\
\hline & {$[0.114]^{* *}$} & [0.103] & [0.108] & {$[0.108]$} & [0.114] & [0.100] & {$[0.100]^{* *}$} \\
\hline \multirow[t]{2}{*}{ IMF Onset (t-3) } & 0.1301 & 0.0761 & 0.0071 & -0.0603 & 0.0231 & -0.1149 & -0.0890 \\
\hline & [0.105] & [0.139] & [0.112] & {$[0.113]$} & [0.106] & [0.118] & [0.105] \\
\hline \multirow[t]{2}{*}{ IMF Onset (t-4) } & 0.1415 & -0.0231 & -0.0685 & -0.1612 & -0.0561 & -0.1899 & -0.0918 \\
\hline & [0.101] & [0.099] & [0.091] & [0.096] & [0.101] & [0.119] & {$[0.078]$} \\
\hline Total IMF Effect & $0.791^{* *}$ & 0.195 & -0.144 & -0.388 & -0.114 & $-0.565^{*}$ & $-0.474 * *$ \\
\hline \multirow[t]{2}{*}{ Real GDP growth (t-1) } & 1.2357 & -2.0964 & -2.1245 & -0.3882 & -2.9479 & 1.6964 & -0.6772 \\
\hline & {$[0.617]^{*}$} & {$[0.470]^{* * *}$} & {$[0.475]^{* * *}$} & [0.482] & {$[0.511]^{* * *}$} & {$[0.396]^{* * *}$} & [0.424] \\
\hline \multirow[t]{2}{*}{ Real GDP growth (t-2) } & -1.3664 & 1.0426 & 1.4787 & 0.8836 & 1.6154 & -0.2704 & 0.3204 \\
\hline & {$[0.489]^{* * *}$} & {$[0.766]$} & {$[0.590]^{* *}$} & {$[0.399]^{* *}$} & {$[0.642]^{* *}$} & [0.442] & {$[0.671]$} \\
\hline \multirow[t]{2}{*}{ Real GDP growth (t-3) } & 0.5208 & 0.4880 & 0.1808 & -0.5235 & 0.3090 & -0.8050 & 0.1248 \\
\hline & {$[0.452]$} & [0.865] & [0.733] & [0.499] & [0.715] & {$[0.440]^{*}$} & [0.577] \\
\hline \multirow[t]{2}{*}{ Real GDP growth (t-4) } & -1.2946 & -0.6776 & -0.2880 & 0.9539 & -1.0394 & 1.4859 & -0.4484 \\
\hline & {$[0.421]^{* * *}$} & [0.559] & [0.583] & {$[0.506]^{*}$} & {$[0.492]^{* *}$} & {$[0.386]^{* * *}$} & {$[0.406]$} \\
\hline \multirow[t]{2}{*}{ High Yield Index } & 0.0030 & 0.0036 & 0.0032 & 0.0017 & 0.0018 & 0.0052 & 0.0049 \\
\hline & {$[0.002]$} & {$[0.001]^{* * *}$} & {$[0.001]^{* *}$} & {$[0.002]$} & {$[0.002]$} & {$[0.002]^{* * *}$} & {$[0.002]^{* * *}$} \\
\hline \multirow[t]{2}{*}{ FED Funds Rate (t-1) } & -0.0032 & -0.0679 & -0.0003 & 0.0320 & -0.0057 & 0.0172 & 0.0169 \\
\hline & [0.069] & [0.053] & {$[0.055]$} & [0.067] & {$[0.042]$} & {$[0.072]$} & {$[0.046]$} \\
\hline \multirow[t]{2}{*}{ Any crisis dummy (t-1) } & 0.2260 & 0.2231 & 0.0975 & -0.0775 & 0.2496 & -0.1828 & -0.0169 \\
\hline & {$[0.120]^{*}$} & {$[0.083]^{* * *}$} & [0.103] & [0.119] & {$[0.089]^{* * *}$} & {$[0.093]^{*}$} & {$[0.088]$} \\
\hline \multirow[t]{2}{*}{ KA Openness (t-1) } & -0.5314 & 0.5338 & 0.6152 & 0.5408 & 0.4237 & 0.4956 & 0.1825 \\
\hline & {$[0.375]$} & {$[0.226]^{* *}$} & {$[0.266]^{* *}$} & {$[0.308]^{*}$} & {$[0.222]^{*}$} & {$[0.306]$} & [0.163] \\
\hline \multirow[t]{2}{*}{ VIX Index (t-1) } & -0.0074 & 0.0088 & 0.0211 & 0.0143 & 0.0131 & -0.0072 & -0.0197 \\
\hline & {$[0.011]$} & [0.008] & {$[0.007]^{* * *}$} & {$[0.007]^{*}$} & {$[0.011]$} & {$[0.011]$} & {$[0.011]^{*}$} \\
\hline TIME TREND & YES & YES & YES & YES & YES & YES & YES \\
\hline YEAR EFFECTS & YES & YES & YES & YES & YES & YES & YES \\
\hline Observations & 2,374 & 2,430 & 2,430 & 2,430 & 2,430 & 2,430 & 2,430 \\
\hline Number of Countries & 43 & 44 & 44 & 44 & 44 & 44 & 44 \\
\hline Adjusted R-squared & 0.138 & 0.155 & 0.214 & 0.185 & 0.162 & 0.235 & 0.102 \\
\hline
\end{tabular}

Robust standard errors in brackets. ${ }^{* * *} p<0.01,{ }^{* *} p<0.05,{ }^{*} p<0.1$. CU stand for the current account, TGF for total gross flows and PGF for private gross flows. Gross inflows and outflows refer to the flows by direction. Finally, foreigner inflows is CIF and residents' outflows is COD. KA Openness refers to the Chin-Ito Index. 
Table 6a: IV Estimation (first stage): Determinants of IMF lending

\begin{tabular}{|c|c|c|c|c|c|}
\hline \multicolumn{2}{|r|}{ Variables } & \multirow{2}{*}{$\begin{array}{c}\text { IMF presence } \\
-0.1216\end{array}$} & \multirow{2}{*}{$\begin{array}{c}\text { IMF presence } \\
-0.1162\end{array}$} & \multirow{2}{*}{$\begin{array}{c}\text { IMF presence } \\
-0.1071\end{array}$} & \multirow{2}{*}{$\begin{array}{c}\text { IMF presence } \\
-0.1082\end{array}$} \\
\hline Domestic politics & Dictatorship dummy & & & & \\
\hline & & {$[0.025]^{* * *}$} & {$[0.026]^{* * *}$} & {$[0.026]^{* * *}$} & {$[0.026]^{* * *}$} \\
\hline & Elections dummy & -0.0118 & -0.0121 & -0.0112 & -0.0115 \\
\hline & & {$[0.006]^{* *}$} & {$[0.006]^{* *}$} & {$[0.006]^{* *}$} & {$[0.006]^{* *}$} \\
\hline \multirow[t]{5}{*}{ Geo-politics } & Presence in UN Security & & 0.0185 & 0.0205 & 0.0199 \\
\hline & Council & & [0 011$] *$ & [0 0111* & [0 011]* \\
\hline & Alignment with the US at & & {$[0.011]^{*}$} & {$[0.011]^{*}$} & {$[0.011]^{*}$} \\
\hline & $\begin{array}{l}\text { Alignment with the US at } \\
\text { UN voting }\end{array}$ & & 0.5029 & 0.5351 & 0.539 \\
\hline & & & {$[0.266]^{*}$} & {$[0.260]^{* *}$} & {$[0.268]^{* *}$} \\
\hline \multirow{4}{*}{$\begin{array}{l}\text { Official sector } \\
\text { politics }\end{array}$} & Paris Club deal dummy & & & 0.3092 & 0.3108 \\
\hline & & & & {$[0.053]^{* * *}$} & {$[0.053]^{* * *}$} \\
\hline & ODA provided by the US & & & 14,348 & 16,639 \\
\hline & & & & {$[0.427]^{* * *}$} & {$[0.368]^{* * *}$} \\
\hline IMF internal & Quota at the IMF & & & & 0.0096 \\
\hline politics & & & & & {$[0.033]$} \\
\hline \multicolumn{2}{|l|}{ Observations } & 3,849 & 3,777 & 3,767 & 3,767 \\
\hline \multicolumn{2}{|c|}{ Number of countries } & 57 & 56 & 56 & 56 \\
\hline
\end{tabular}

Table 6b: IV Estimation: Second Stage

\begin{tabular}{lccccccc}
\hline VARIABLES & CU & TGF & PGF & $\begin{array}{c}\text { GROSS } \\
\text { INFLOWS }\end{array}$ & $\begin{array}{c}\text { GROSS } \\
\text { OUTFLOWS }\end{array}$ & $\begin{array}{c}\text { FOREIGNERS } \\
\text { INFLOWS }\end{array}$ & $\begin{array}{c}\text { RESIDENTS } \\
\text { OUTFLOWS }\end{array}$ \\
\hline IMF Onset IV (t-1) & 0.6524 & -0.0587 & -0.4881 & -0.5951 & -0.1680 & -0.4993 & -0.0714 \\
& {$[0.261]^{* *}$} & {$[0.242]$} & {$[0.174]^{* * *}$} & {$[0.183]^{* * *}$} & {$[0.225]$} & {$[0.190]^{* *}$} & {$[0.214]$} \\
IMF Onset IV (t-2) & 0.6020 & -0.0460 & -0.1018 & -0.2136 & -0.1144 & -0.4117 & -0.5875 \\
& {$[0.302]^{*}$} & {$[0.208]$} & {$[0.235]$} & {$[0.251]$} & {$[0.254]$} & {$[0.233]^{*}$} & {$[0.221]^{* *}$} \\
IMF Onset IV (t-3) & 0.3619 & -0.0648 & -0.1291 & -0.2747 & -0.0351 & -0.3858 & -0.3051 \\
& {$[0.239]$} & {$[0.294]$} & {$[0.252]$} & {$[0.262]$} & {$[0.224]$} & {$[0.248]$} & {$[0.201]$} \\
IMF Onset IV (t-4) & 0.2224 & -0.0170 & -0.1883 & -0.5385 & 0.0387 & -0.6868 & -0.1510 \\
& {$[0.246]$} & {$[0.264]$} & {$[0.211]$} & {$[0.180]^{* * *}$} & {$[0.298]$} & {$[0.260]^{* *}$} & {$[0.207]$} \\
\hline Total IMF Effect & $1.839^{* *}$ & -0.187 & -0.907 & $-1.622^{* *}$ & -0.279 & $-1.984^{* * *}$ & $-1.115^{* *}$ \\
\hline Controls & YES & YES & YES & YES & YES & YES & YES \\
Time trend & YES & YES & YES & YES & YES & YES & YES \\
Year effects & YES & YES & YES & YES & YES & YES & YES \\
\hline Observations & 2,302 & 2,354 & 2,354 & 2,354 & 2,354 & 2,354 & 2,354 \\
Number of Countries & 43 & 44 & 44 & 44 & 44 & 44 & 44 \\
Adjusted R-squared & 0.138 & 0.152 & 0.213 & 0.189 & 0.158 & 0.247 & 0.105 \\
\hline
\end{tabular}

Robust standard errors in brackets. ${ }^{* * *} p<0.01,{ }^{* *} p<0.05,{ }^{*} p<0.1$. CU stand for the current account, TGF for total gross flows and PGF for private gross flows. Gross inflows and outflows refer to the flows by direction. Finally, foreigner inflows is CIF and residents' outflows is COD. Controls included are the same as in table 4. 
Table 7: Disaggregating by direction and origin of flows

\begin{tabular}{lcccc}
\hline VARIABLES & Private Inflows & Private Inflows & Private Outflows & Private Outflows \\
& From Liabilities & From Assets & From Assets & From Liabilities \\
\hline LSDV ESTIMATION & & & & -0.006 \\
\hline Total IMF Effect after 4 quarters & $-0.168^{* *}$ & $0.076^{* *}$ & -0.059 & {$[0.882]$} \\
P-Value Wald Test & {$[0.044]$} & {$[0.045]$} & {$[0.379]$} & 2430 \\
Observations & 2430 & 2430 & 2430 & 44 \\
Number of Countries & 44 & 44 & 44 & 0.136 \\
Adjusted R-squared & 0.19 & 0.085 & 0.168 & -0.151 \\
\hline IV ESTIMATION (SECOND STAGE) & & & -0.421 & {$[0.829]$} \\
\hline Total IMF Effect after 4 quarters & $-2.195^{* * *}$ & $1.089^{* *}$ & {$[0.482]$} & 2354 \\
Observations & {$[0.002]$} & {$[0.026]$} & 2354 & 44 \\
Number of Countries & 2354 & 2354 & 44 & 0.138 \\
Adjusted R-squared & 44 & 44 & 0.166 & YES \\
\hline Controls & 0.199 & 0.084 & YES & YES \\
Time trend & YES & YES & YES & YES \\
Year effects & YES & YES & YES & \\
\hline YObUSt Standard & YES & & \\
\hline
\end{tabular}

Robust standard errors in brackets. ${ }^{* * *} p<0.01,{ }^{* *} p<0.05,{ }^{*} p<0.1$. Controls included are the same as in table 4.

Table 8: Disaggregating by type of flow

\begin{tabular}{|c|c|c|c|c|c|c|}
\hline VARIABLES & FDI INFLOW & FDI OUTFLOW & PI INFLOW & PI OUTFLOW & OI INFLOW & OI OUTFLOW \\
\hline \multicolumn{7}{|l|}{ LSDV ESTIMATION } \\
\hline \multirow[t]{2}{*}{ Total IMF Effect after 4 quarters } & -0.03 & 0.018 & -0.005 & -0.025 & $-0.144^{*}$ & $-0.163 * *$ \\
\hline & [0.459] & {$[0.167]$} & {$[0.8]$} & {$[0.475]$} & {$[0.076]$} & {$[0.022]$} \\
\hline Observations & 2374 & 2322 & 2386 & 2366 & 2374 & 2430 \\
\hline Number of Countries & 43 & 42 & 43 & 43 & 43 & 44 \\
\hline Adjusted R-squared & 0.108 & 0.138 & 0.088 & 0.043 & 0.207 & 0.044 \\
\hline \multicolumn{7}{|l|}{ IV ESTIMATION (SECOND STAGE) } \\
\hline \multirow[t]{2}{*}{ Total IMF Effect after 4 quarters } & $-1.404^{*}$ & 0.605 & -0.573 & -0.327 & $-1.793 * * *$ & $-1.325^{* *}$ \\
\hline & {$[0.075]$} & {$[0.28]$} & {$[0.367]$} & {$[0.632]$} & [0.009] & [0.023] \\
\hline Observations & 2302 & 2254 & 2314 & 2294 & 2302 & 2354 \\
\hline Number of Countries & 43 & 42 & 43 & 43 & 43 & 44 \\
\hline Adjusted R-squared & 0.119 & 0.134 & 0.09 & 0.041 & 0.214 & 0.048 \\
\hline Controls & YES & YES & YES & YES & YES & YES \\
\hline Time trend & YES & YES & YES & YES & YES & YES \\
\hline Year effects & YES & YES & YES & YES & YES & YES \\
\hline
\end{tabular}

Robust standard errors in brackets. ${ }^{* *} p<0.01,{ }^{* *} p<0.05,{ }^{*} p<0.1$. Controls included are the same as in table 4. 
Figure 2: Total and Private Gross Flows IRFs to IMF Onset

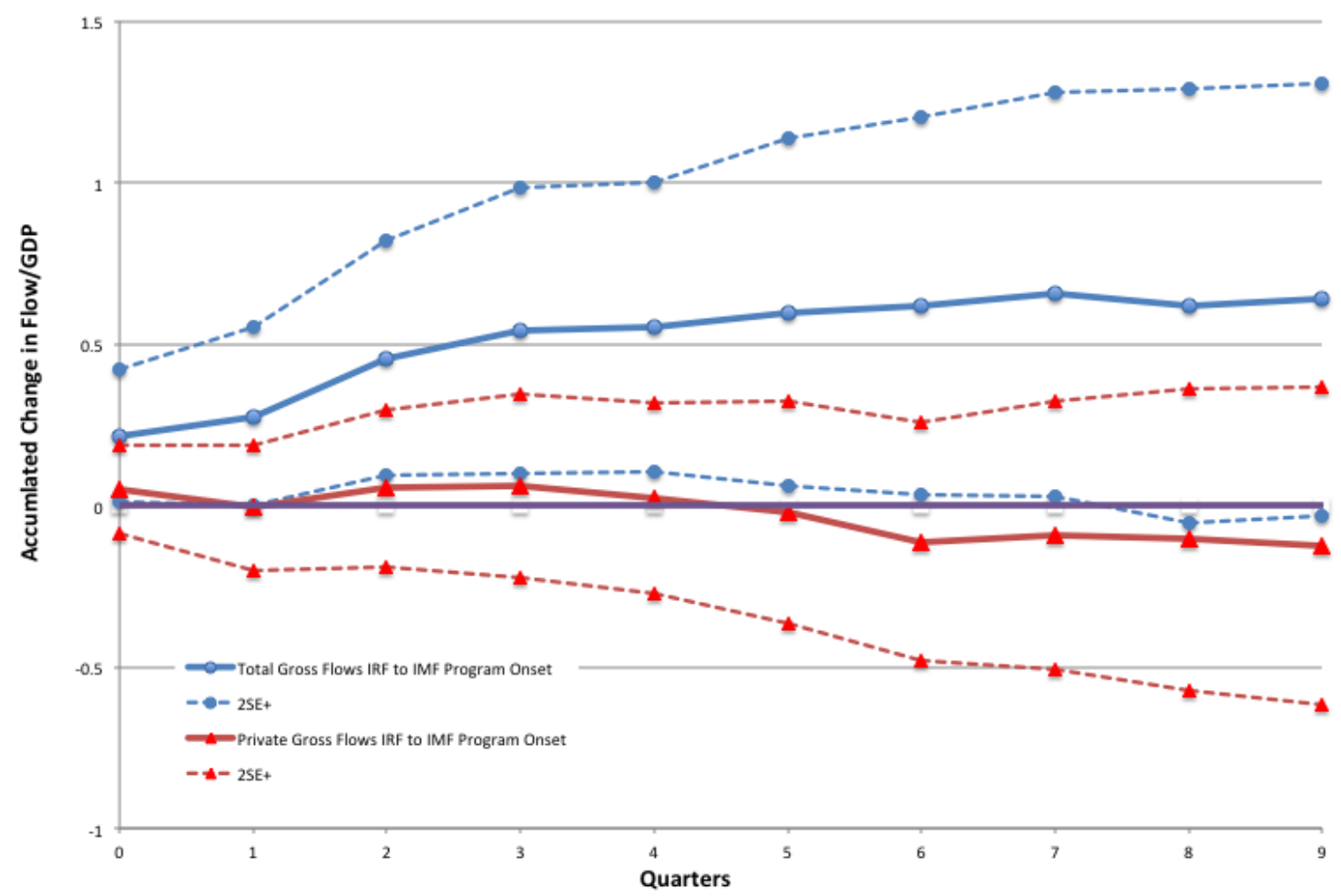

Figure 3: CIF and COD IRFs to IMF Onset

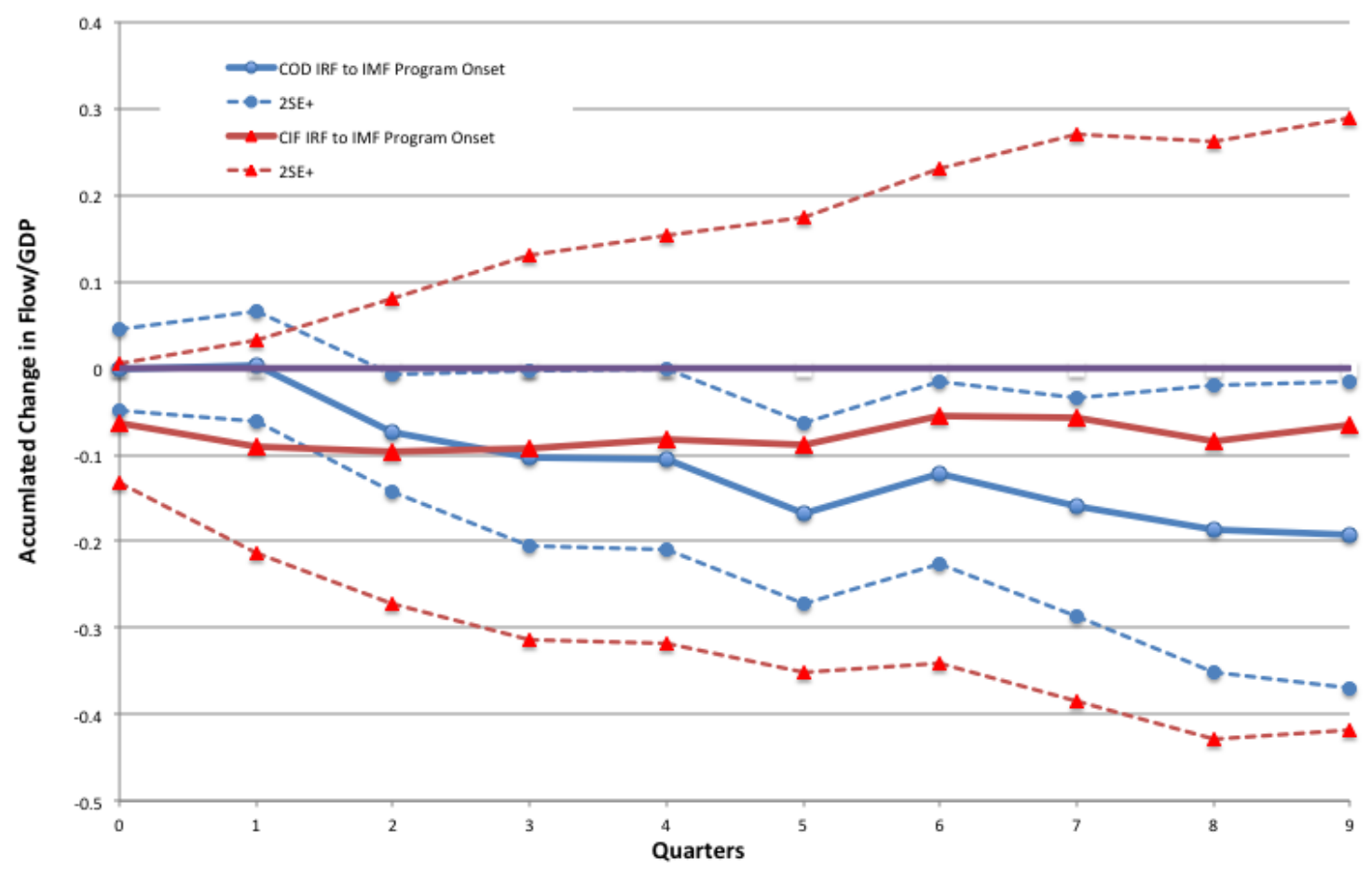


Figure 4: Gross Private Outflows/Inflows IRFs to IMF Onset

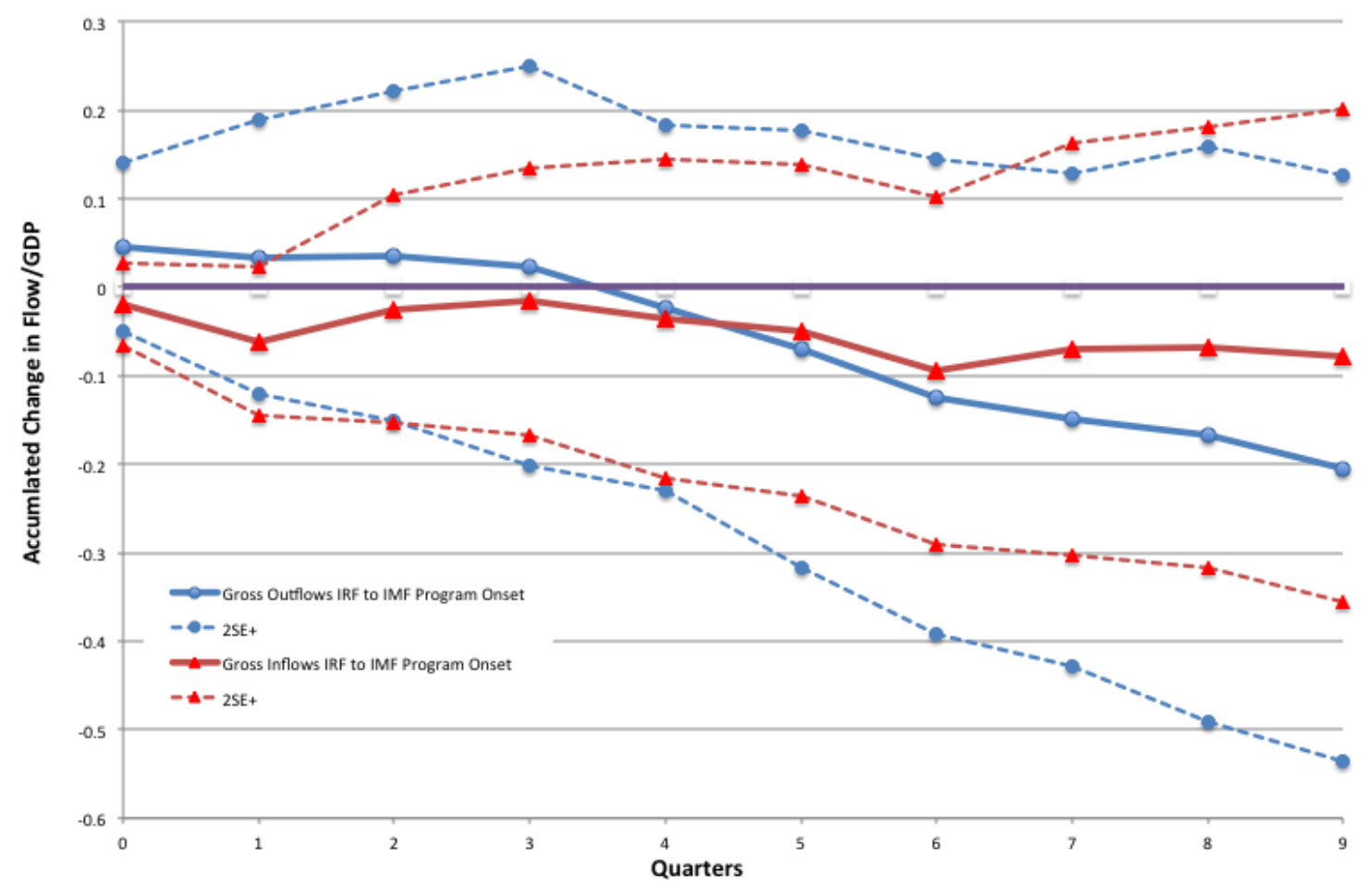


Figure 5: INDIVIDUAL COMPONENTS OF THE NET INFLOW IRFs to IMF Onset

Panel A

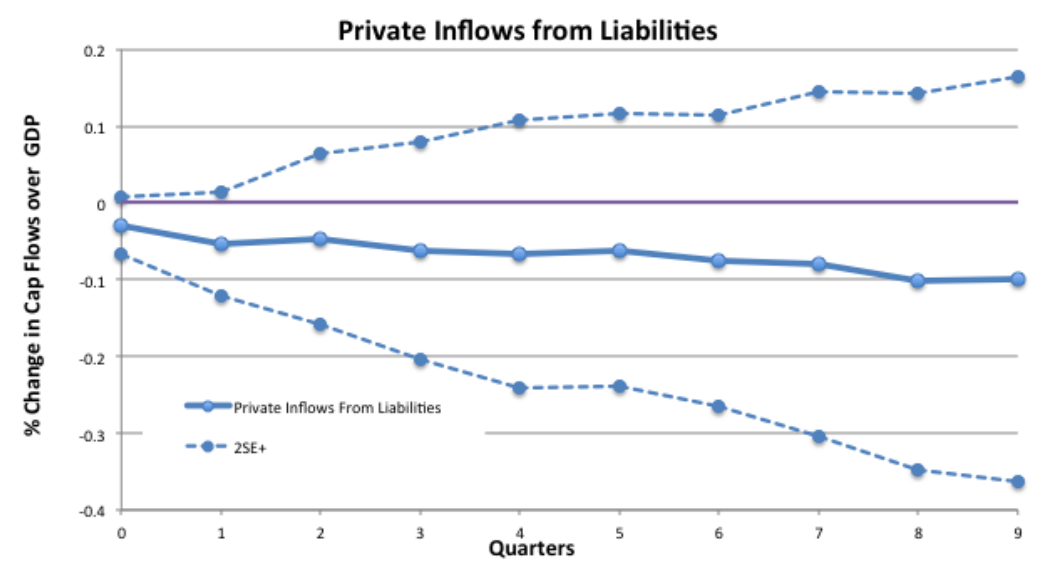

Panel C

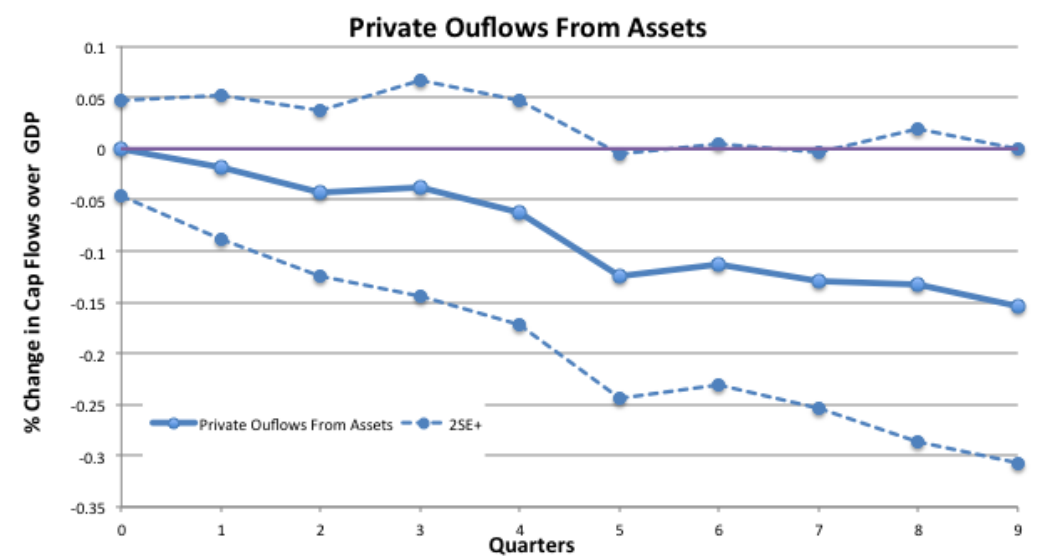

Panel B

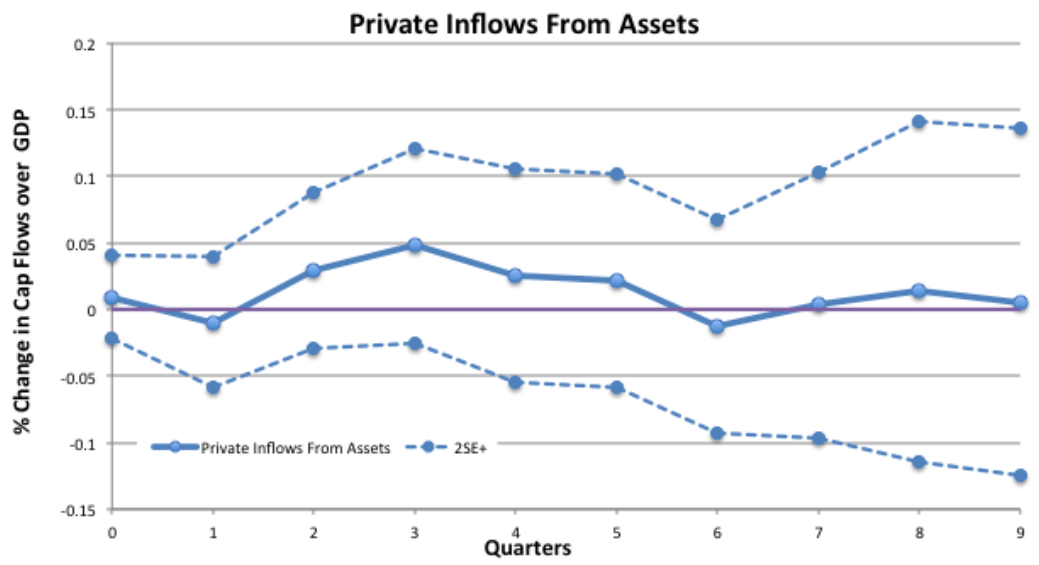

Panel D

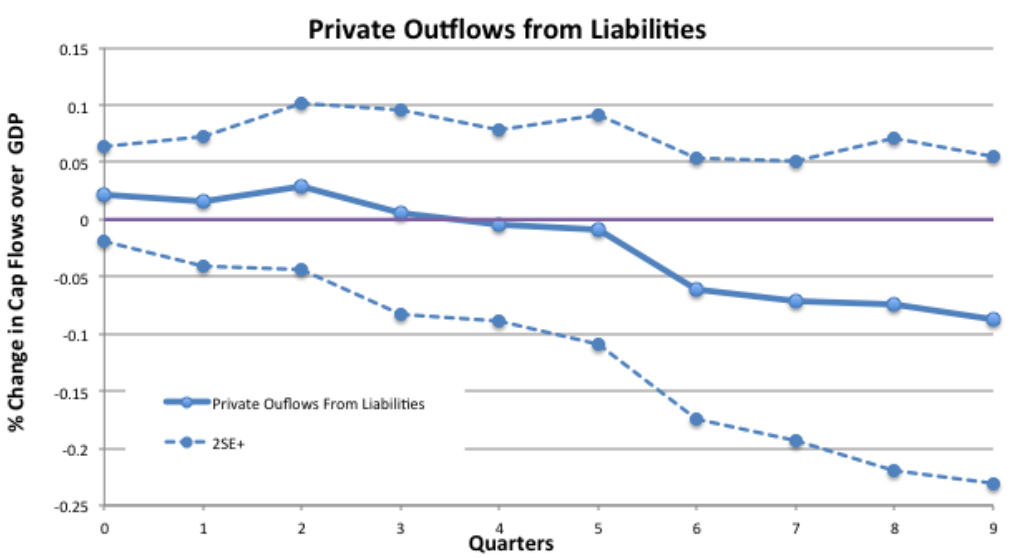


Figure 6: FDI CIF/COD IRFs to IMF Onset

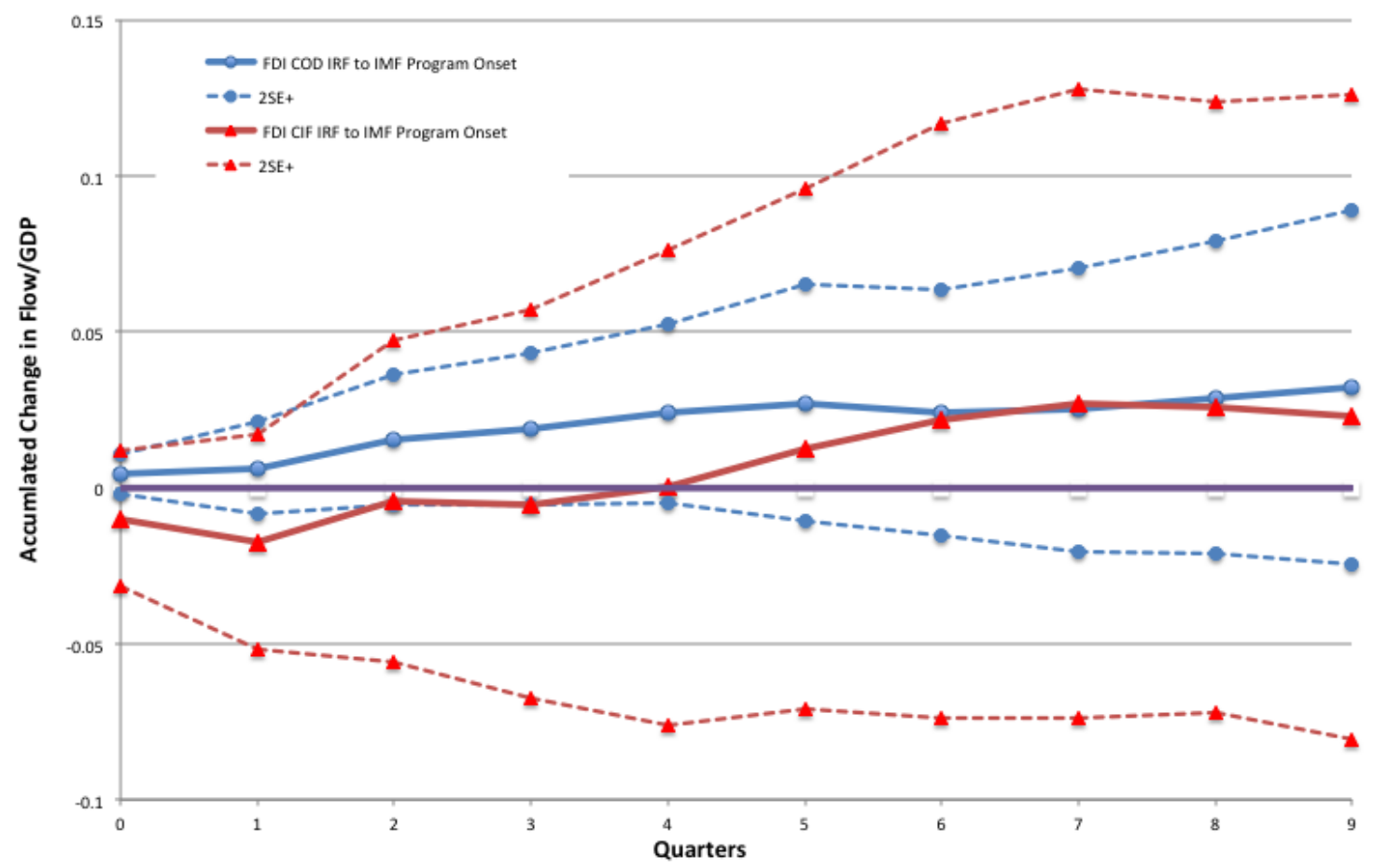

Figure 7: Portfolio Investment CIF/COD IRFs to IMF Onset

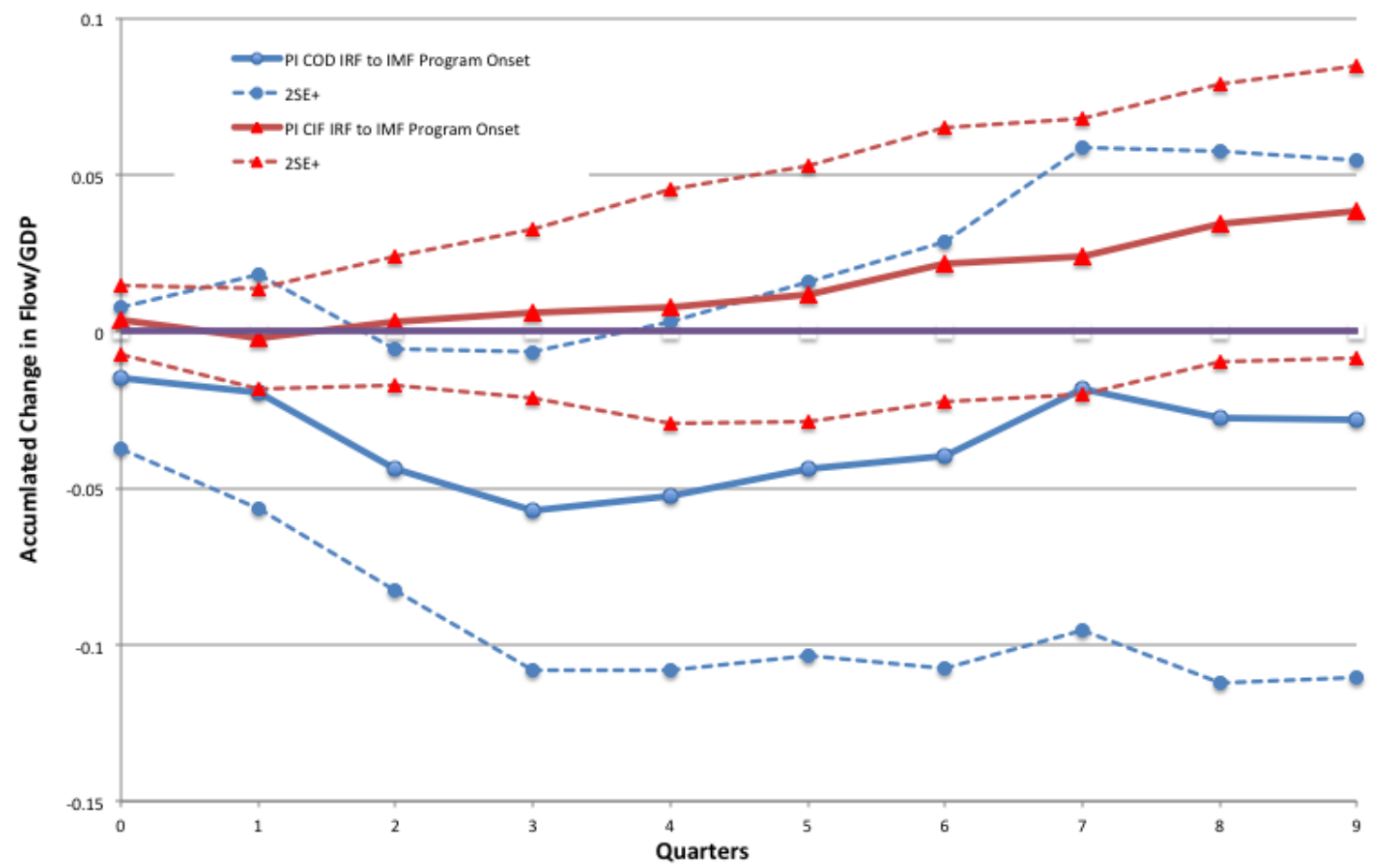


Figure 8: Other Investment CIF/COD IRFs to IMF Onset

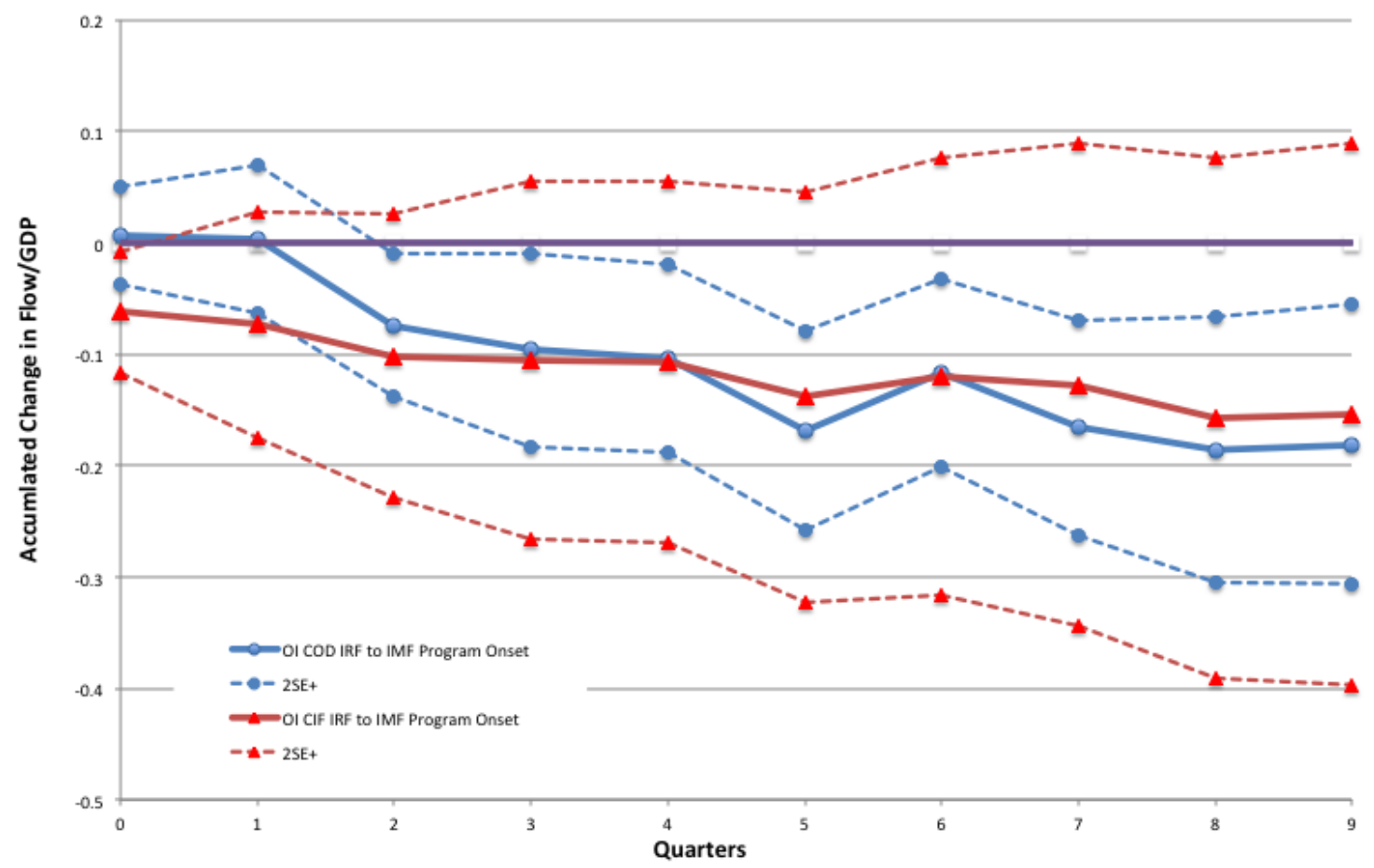

Figure 9: Impulse response to 1 Standard deviation shock to the expectation of IMF Onset

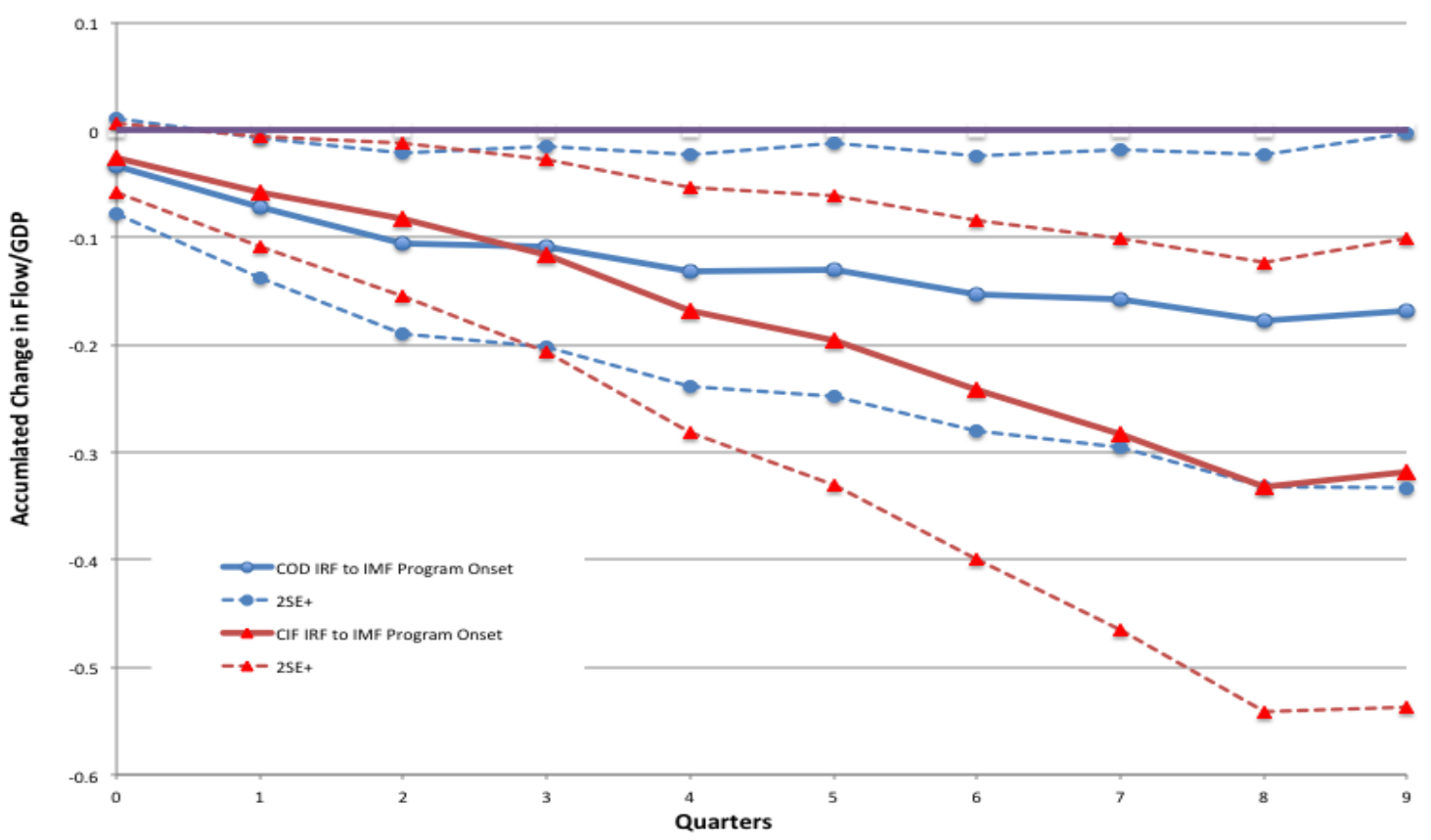


Figure 10: Individual components of the net inflow: IRFs to 1 standard deviation shock to the expectation of IMF Program Onset

\section{Panel A}

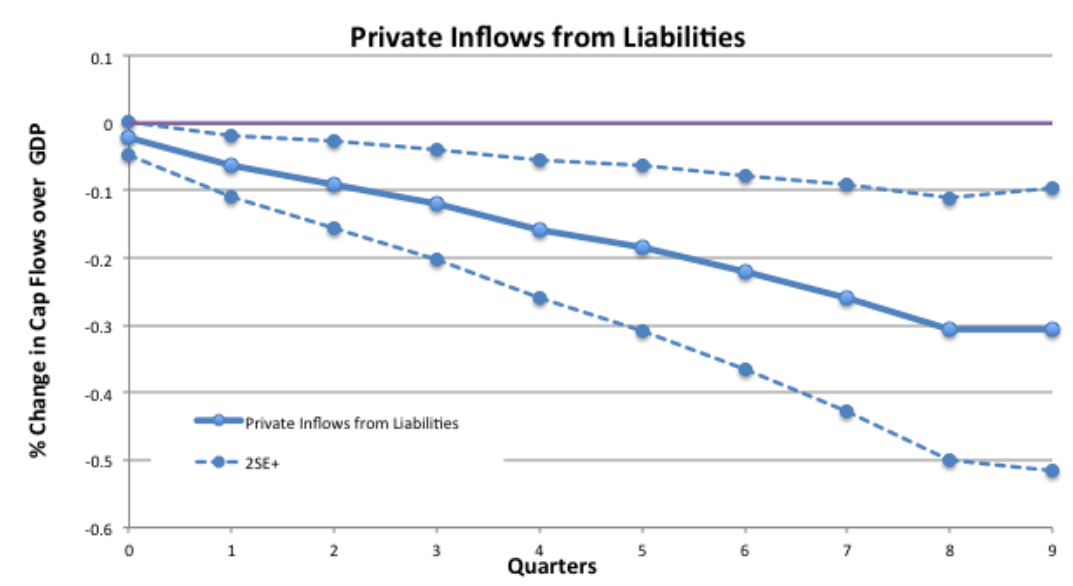

Panel C

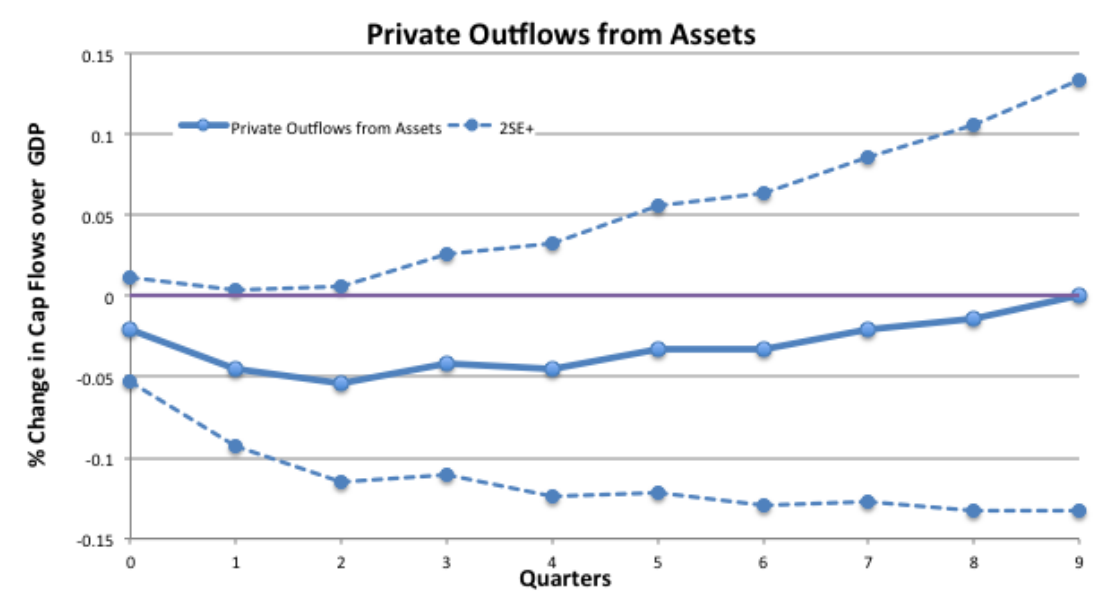

Panel B

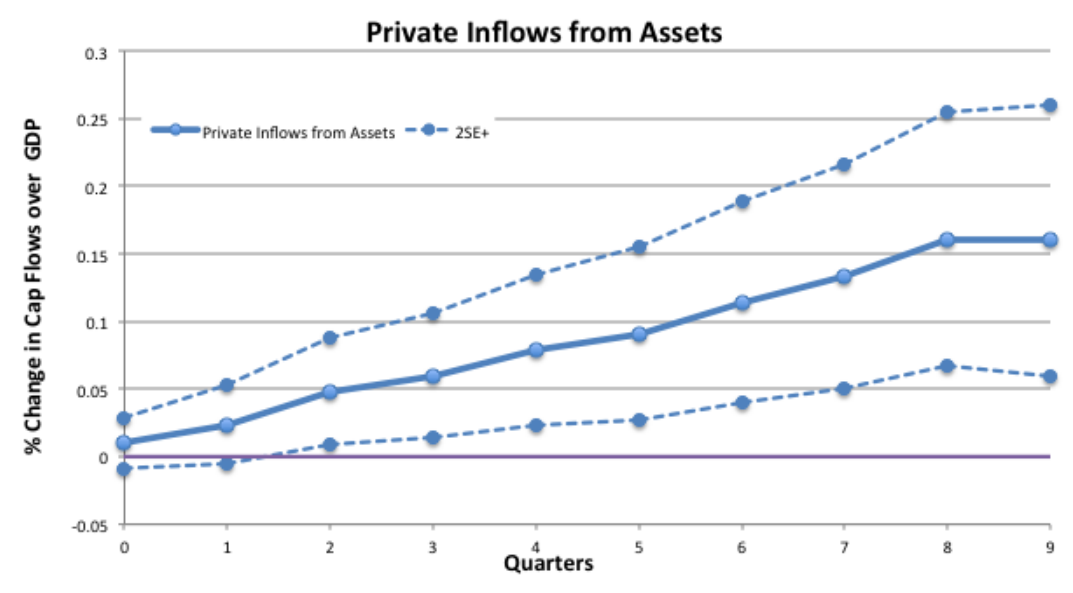

Panel D

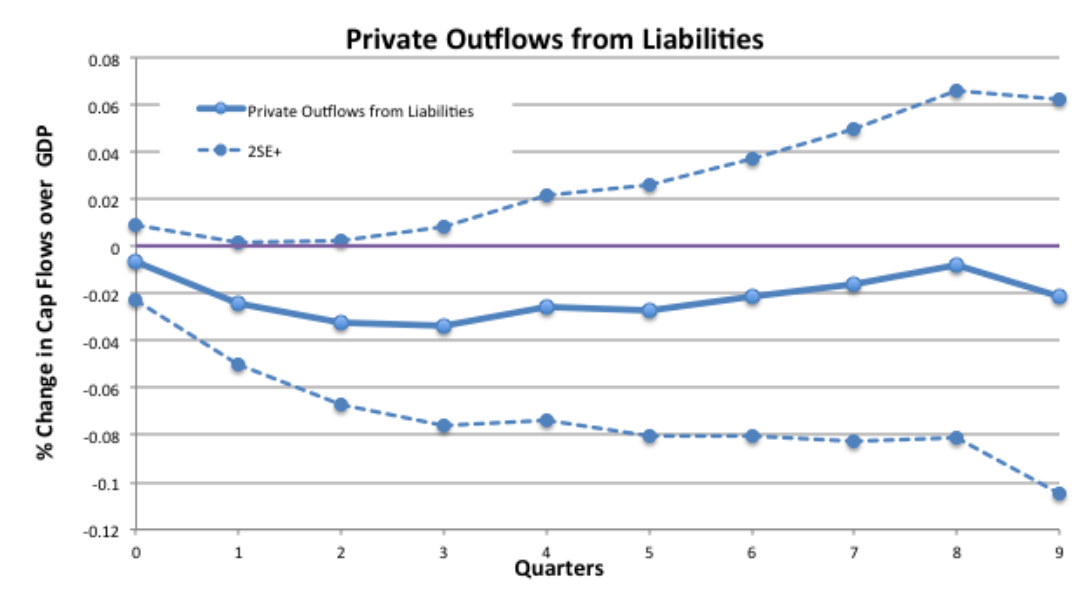


Figure 11: CIF and COD IRFs to IMF Onset controlling for Expectations

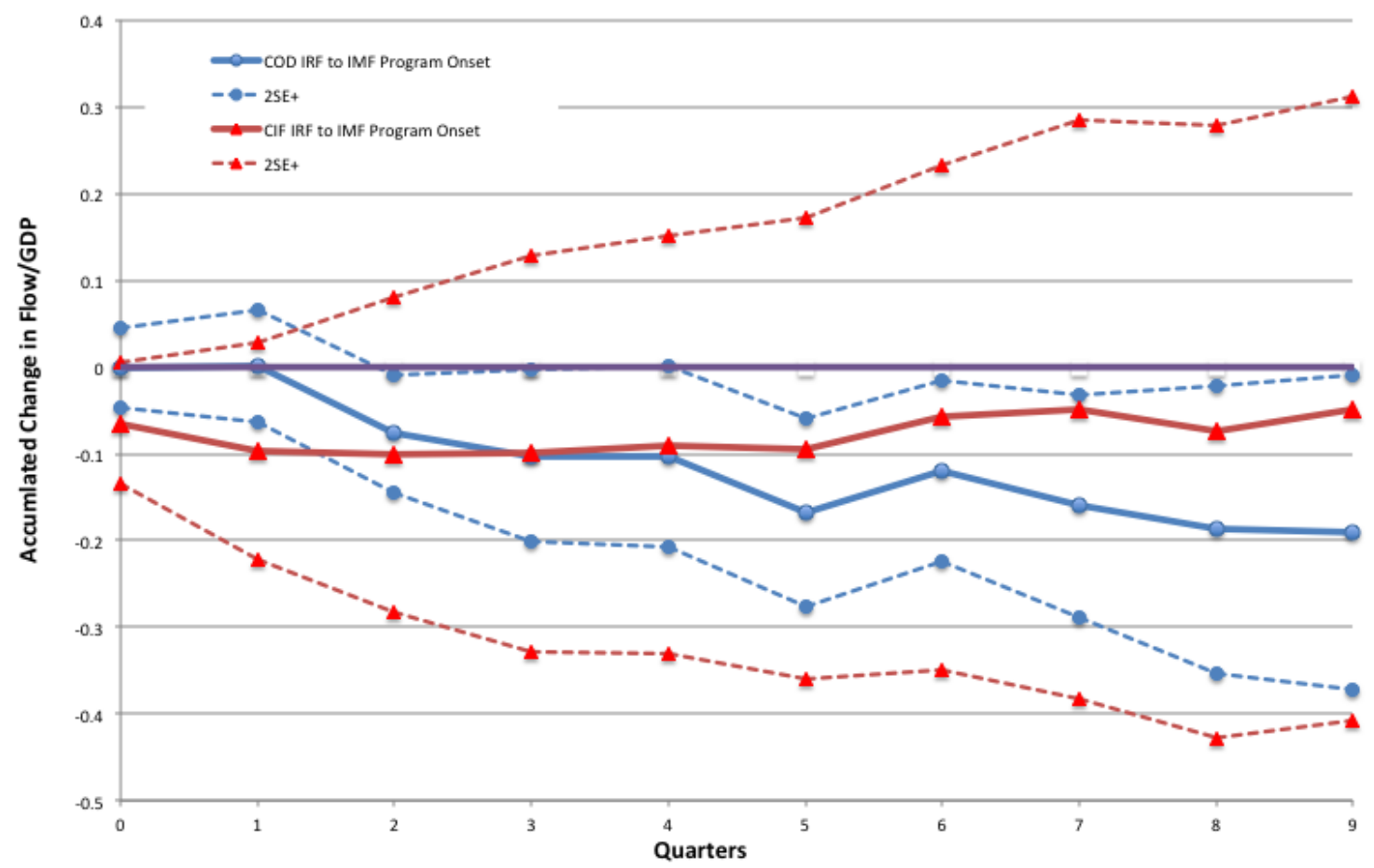

Figure 12: Gross outflows IRF to any type of crisis with and without onset of IMF program

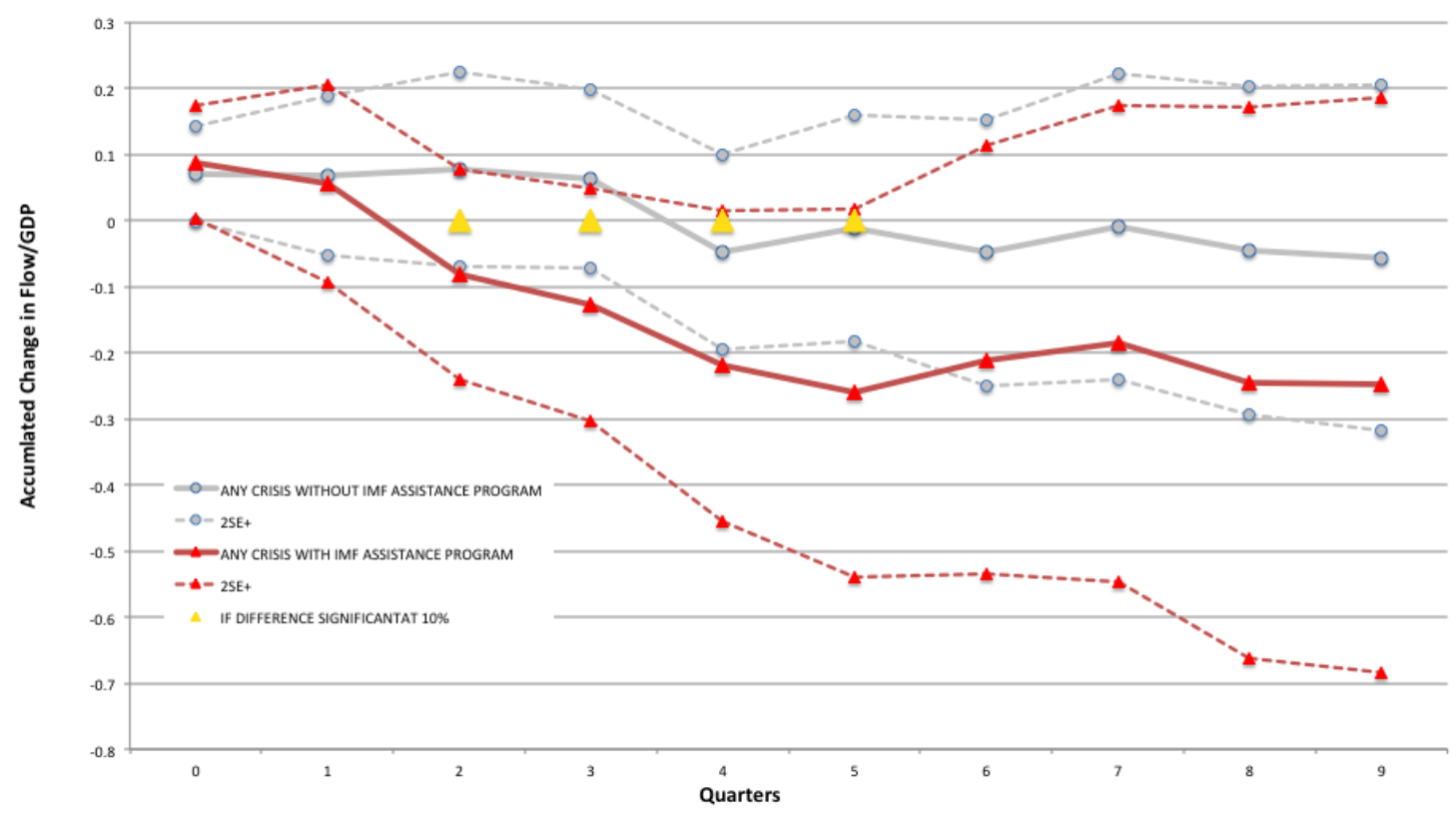


Figure 13: Gross outflows IRF to currency crisis with and without onset of IMF program

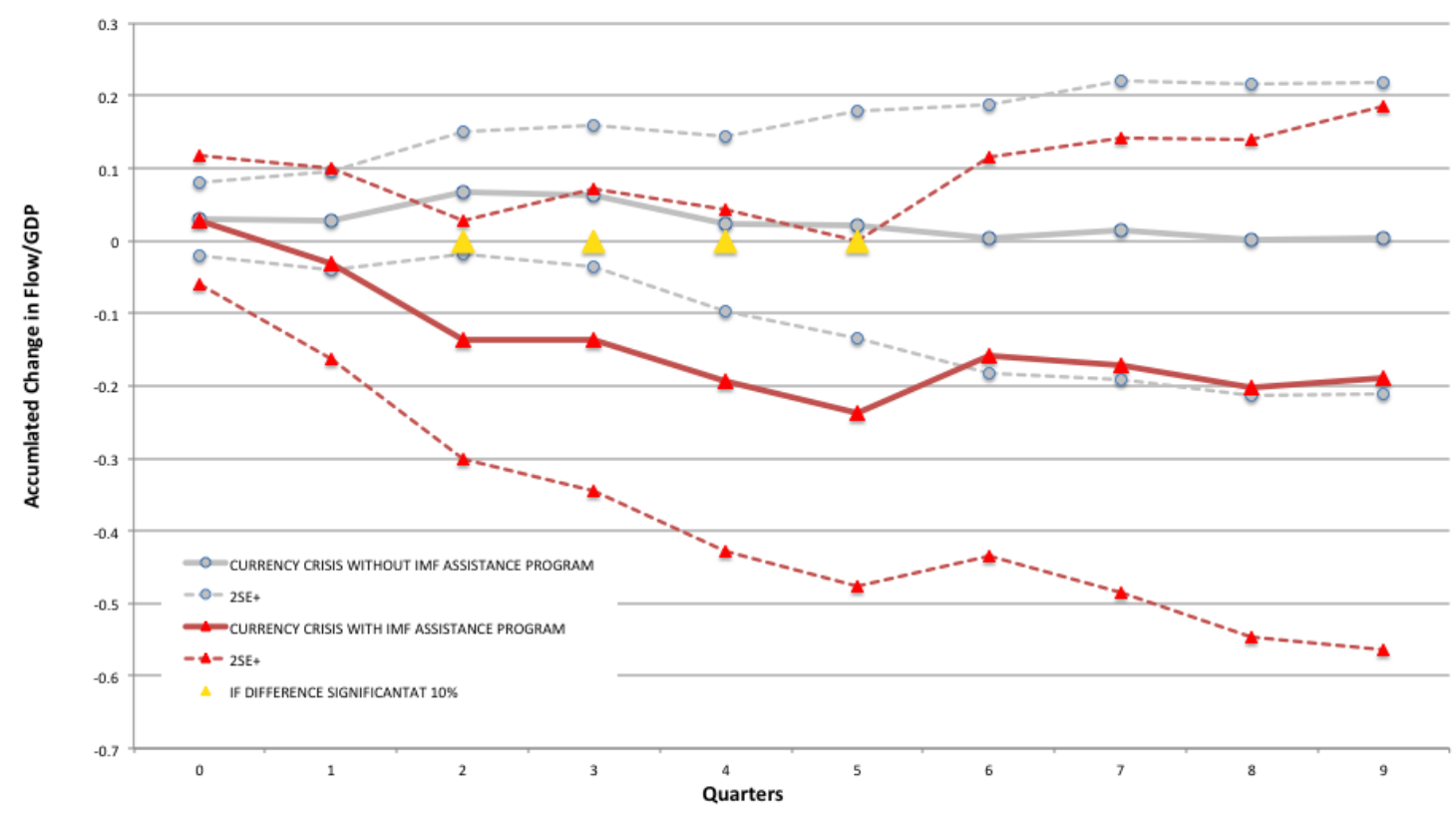

Figure 14: Gross outflows IRF to banking crisis with and without onset of IMF program

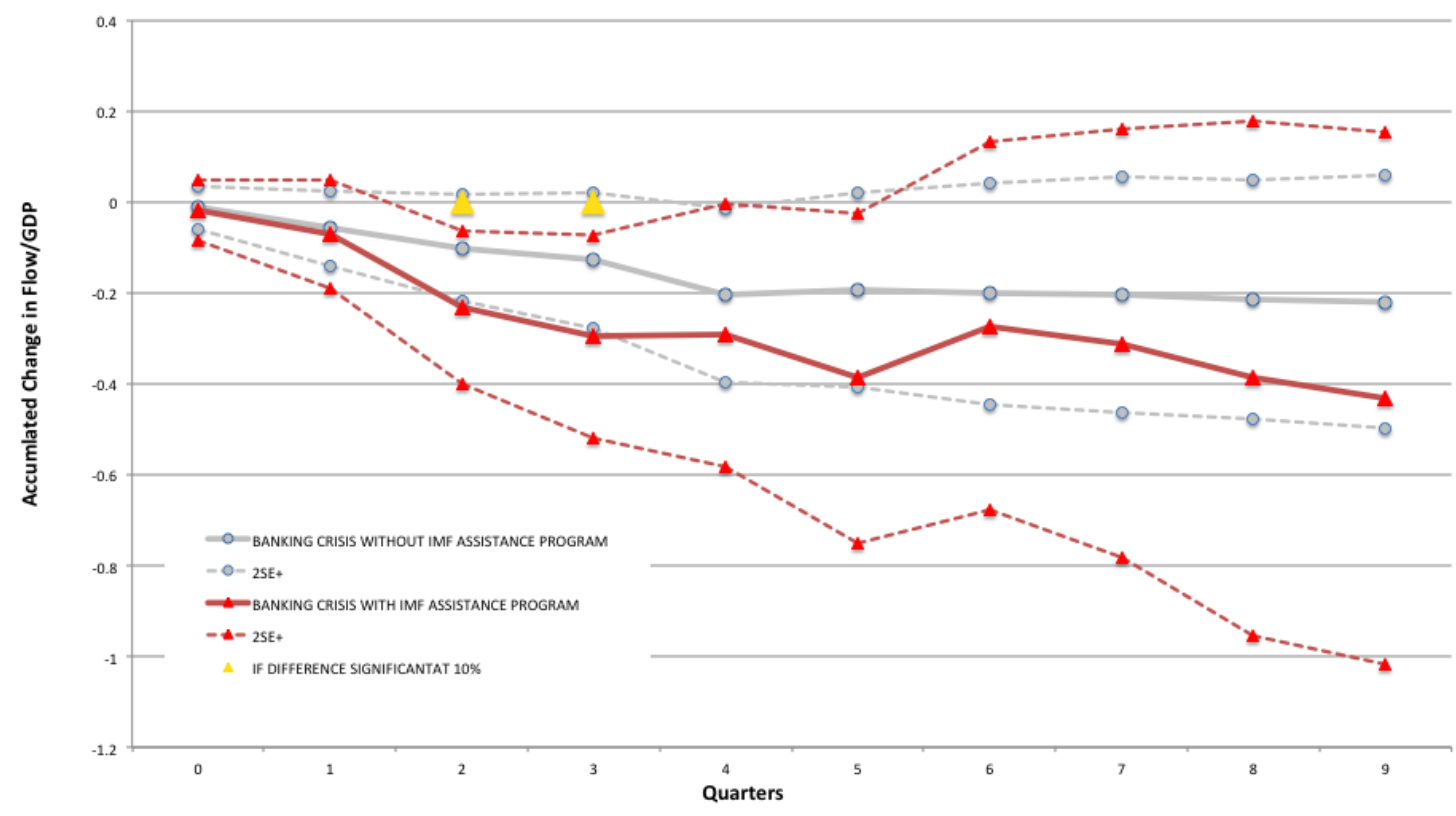


Figure 15: Gross outflows IRF to sovereign domestic debt crisis with and without onset of IMF program

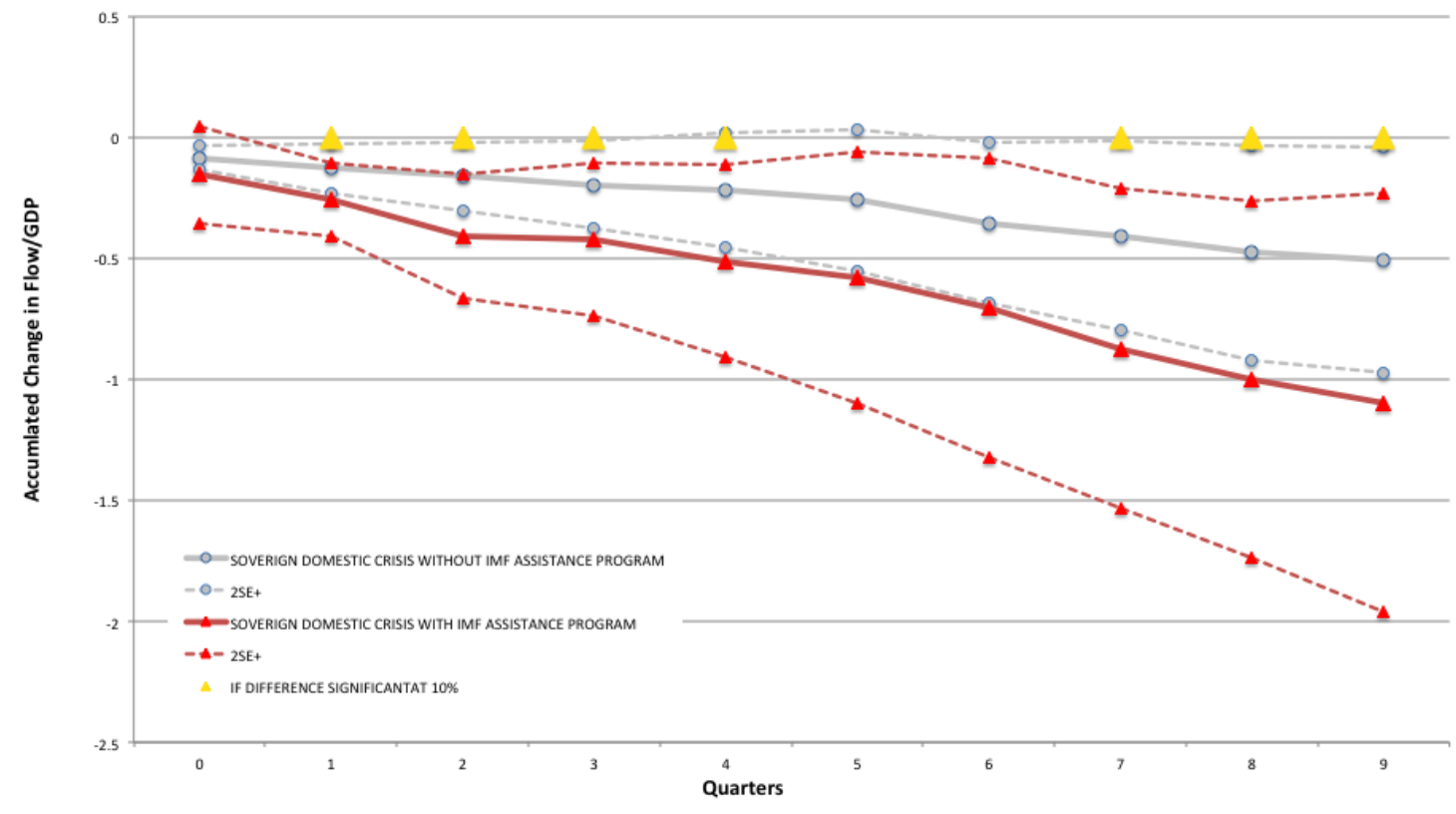

Figure 16: Gross outflows IRF to sovereign external debt crisis with and without onset of IMF program

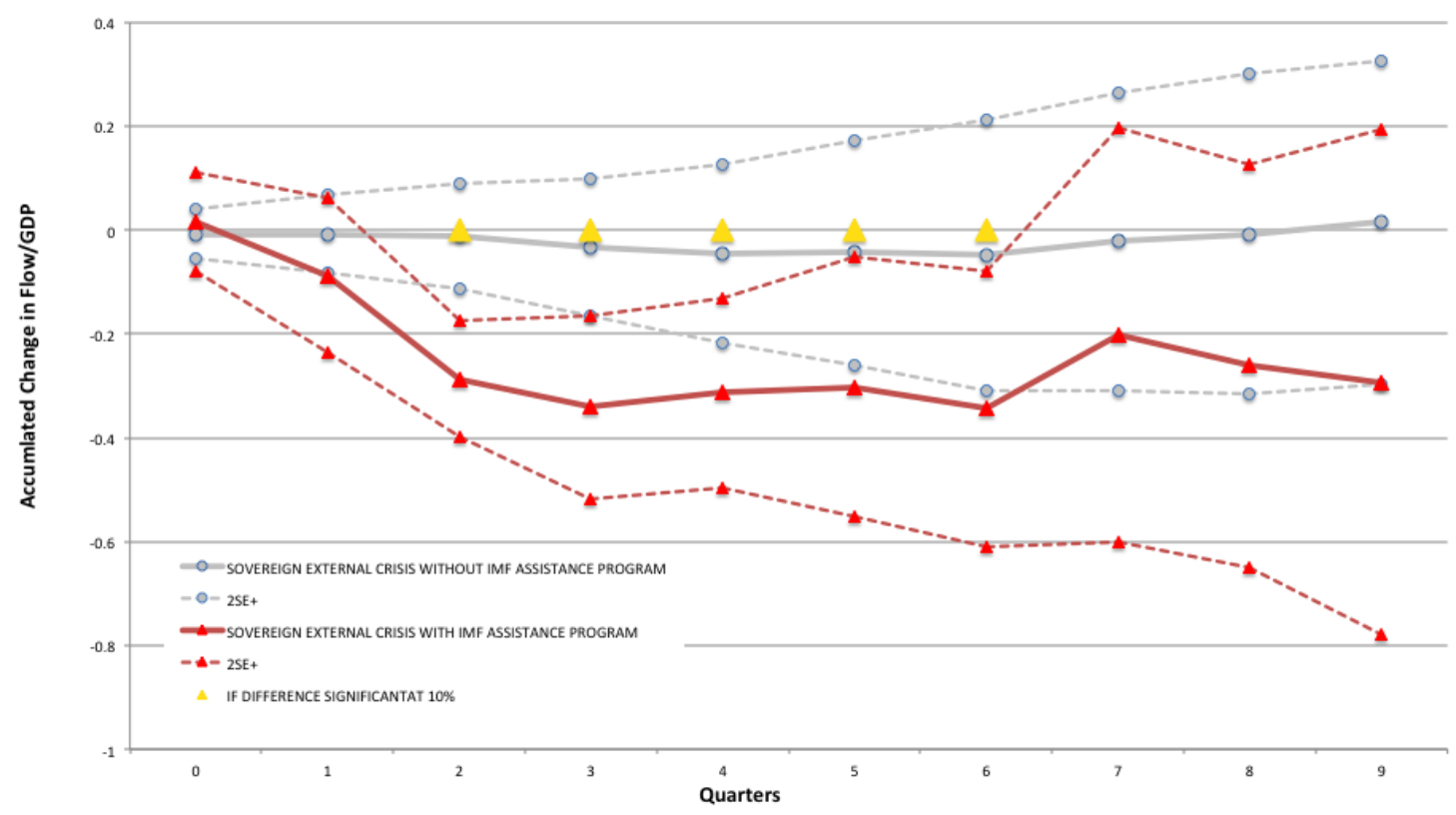


Figure 17: Gross inflows IRF to any type of crisis with and without onset of IMF program

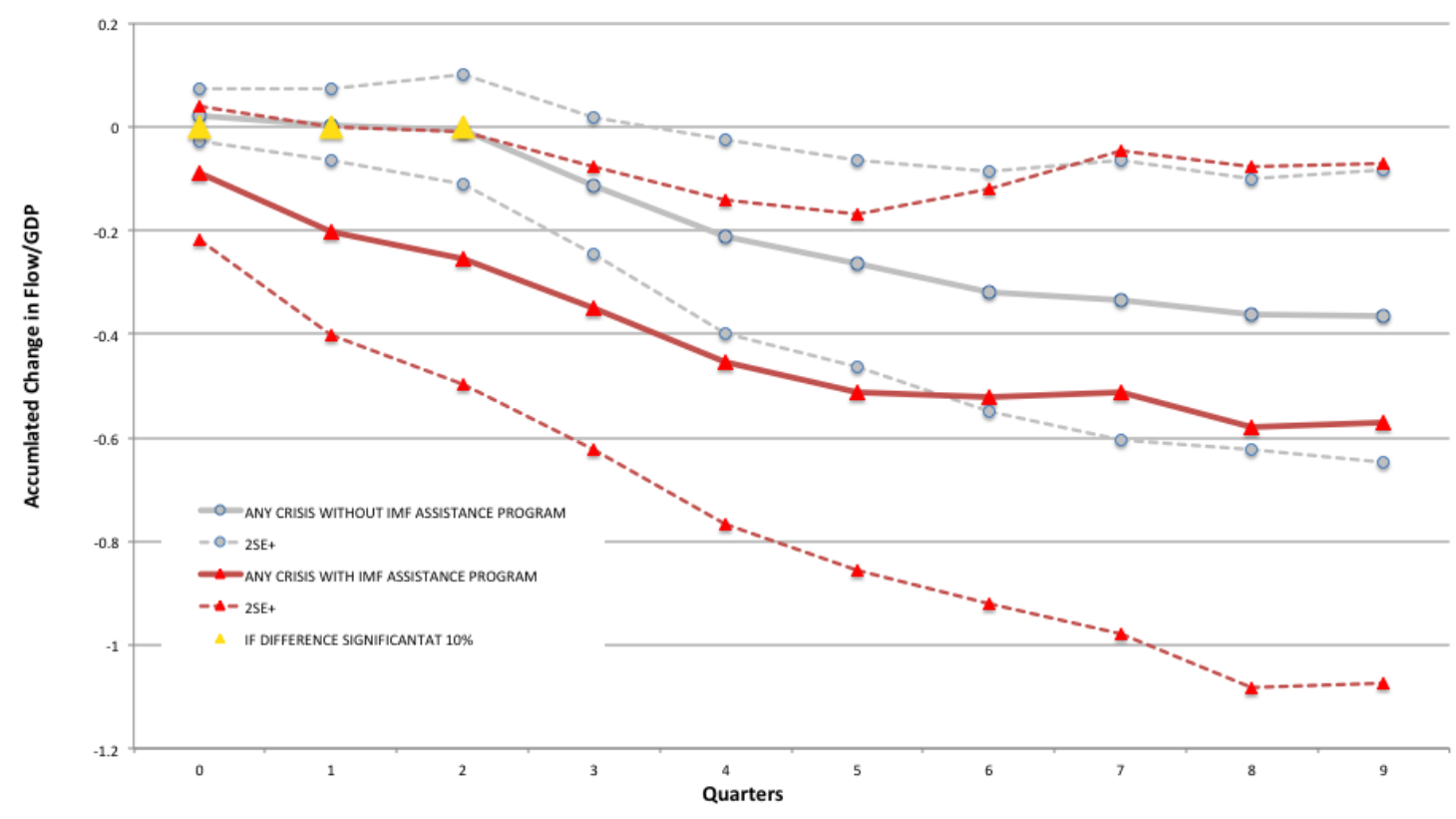

Figure 18: Gross inflows IRF to currency crisis with and without onset of IMF program

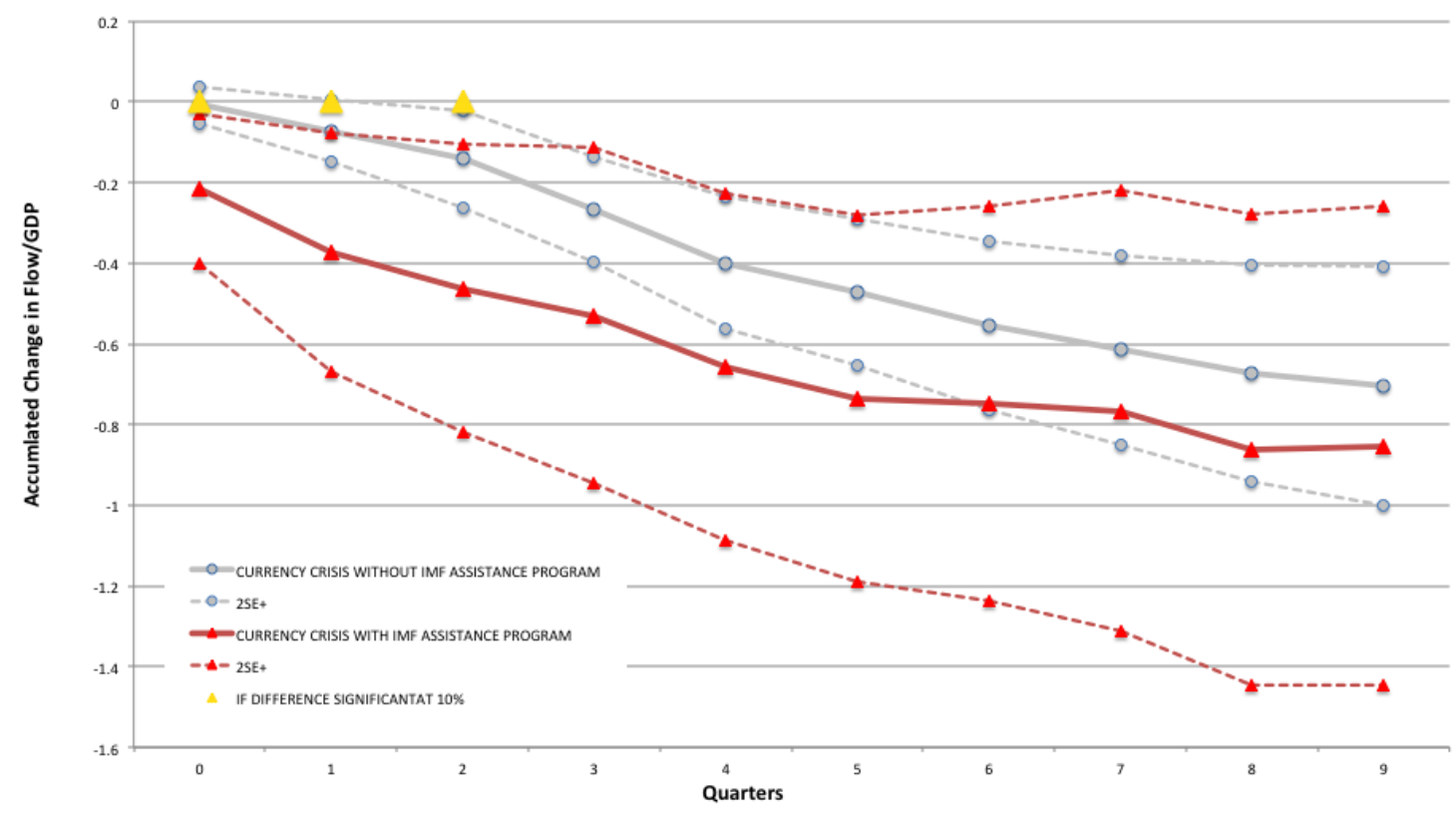


Figure 19: Gross inflows IRF to banking crisis with and without onset of IMF program

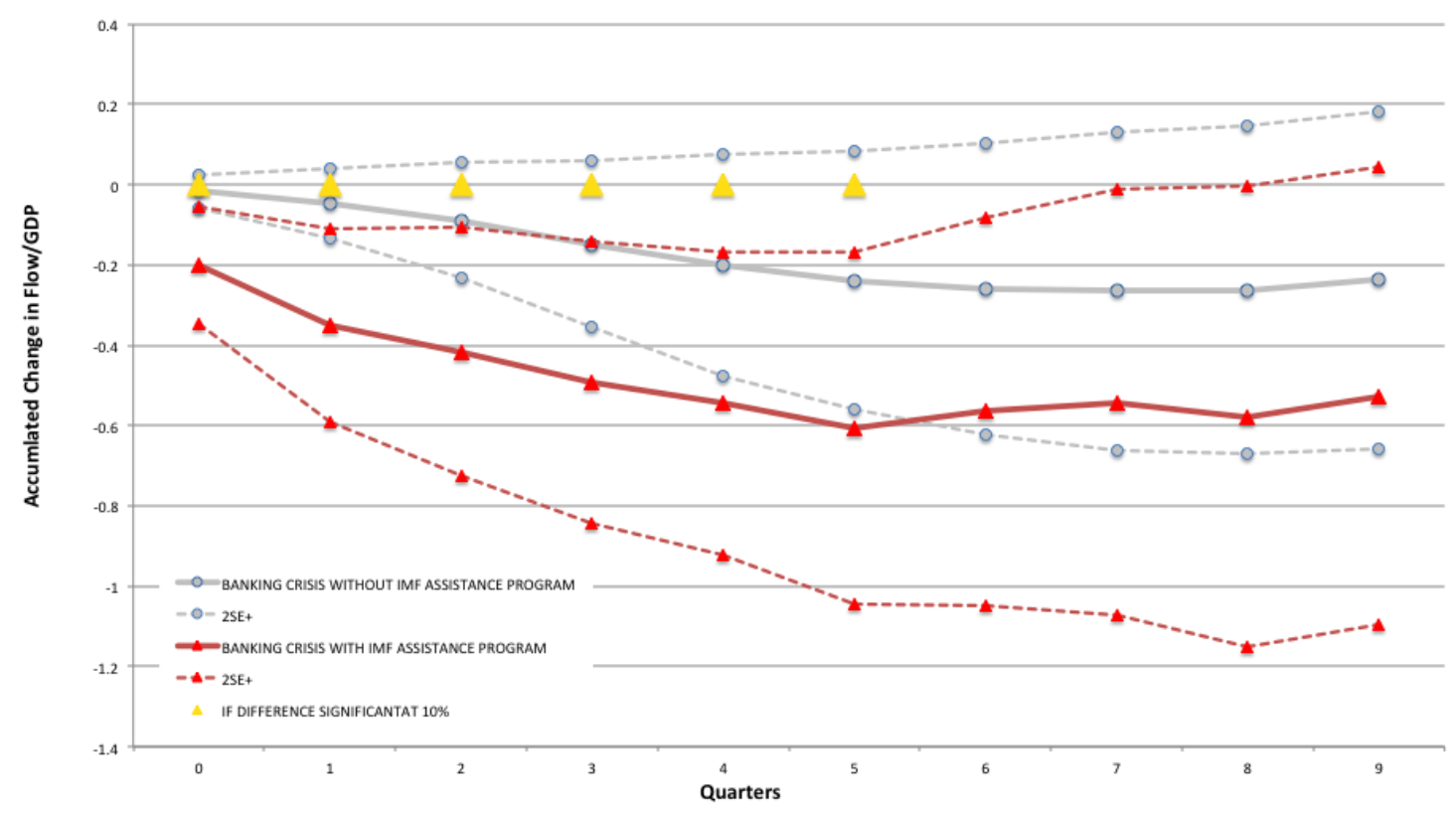

Figure 20: Gross inflows IRF to sovereign domestic debt crisis with and without onset of IMF program

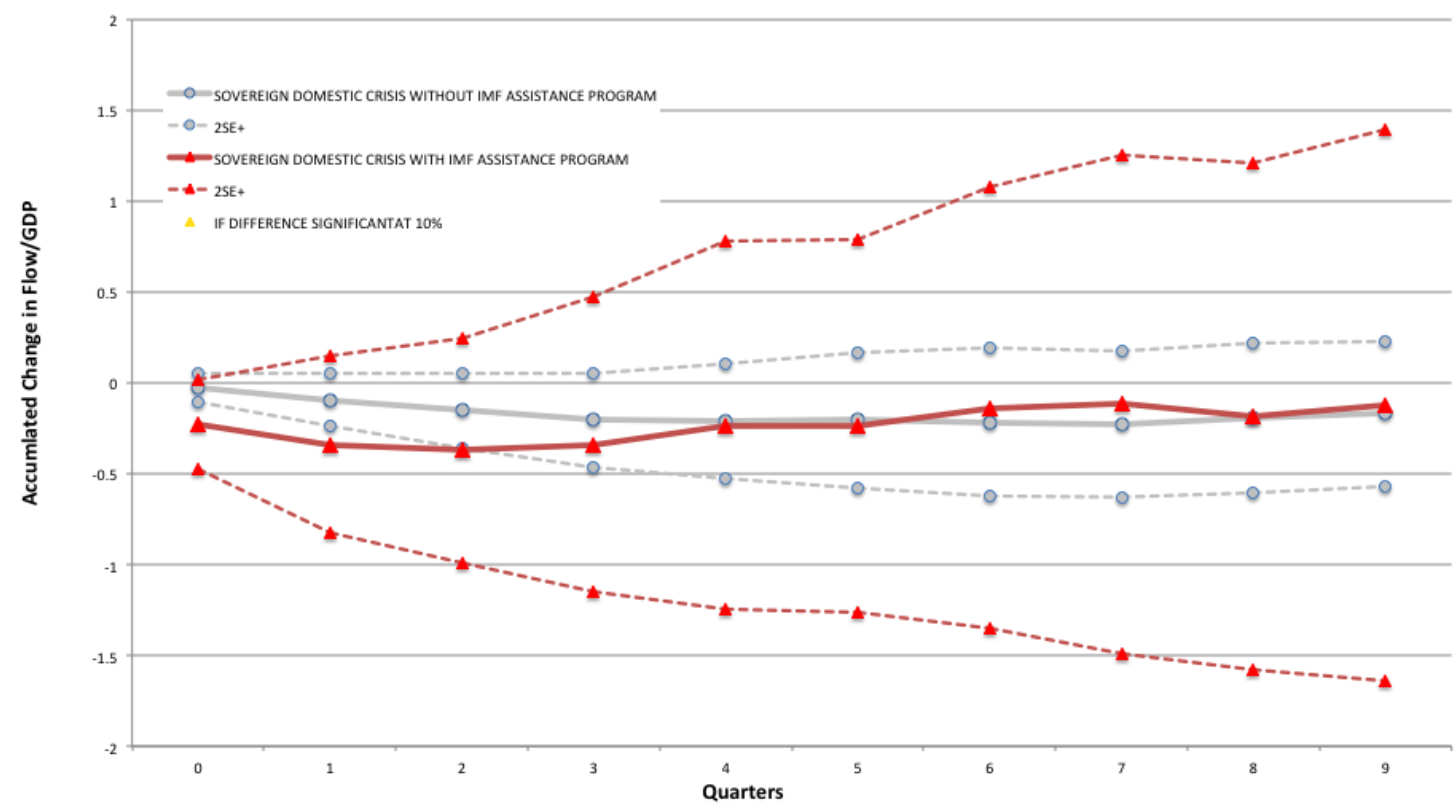


Figure 21: Gross inflows IRF to sovereign external debt crisis with and without onset of IMF program

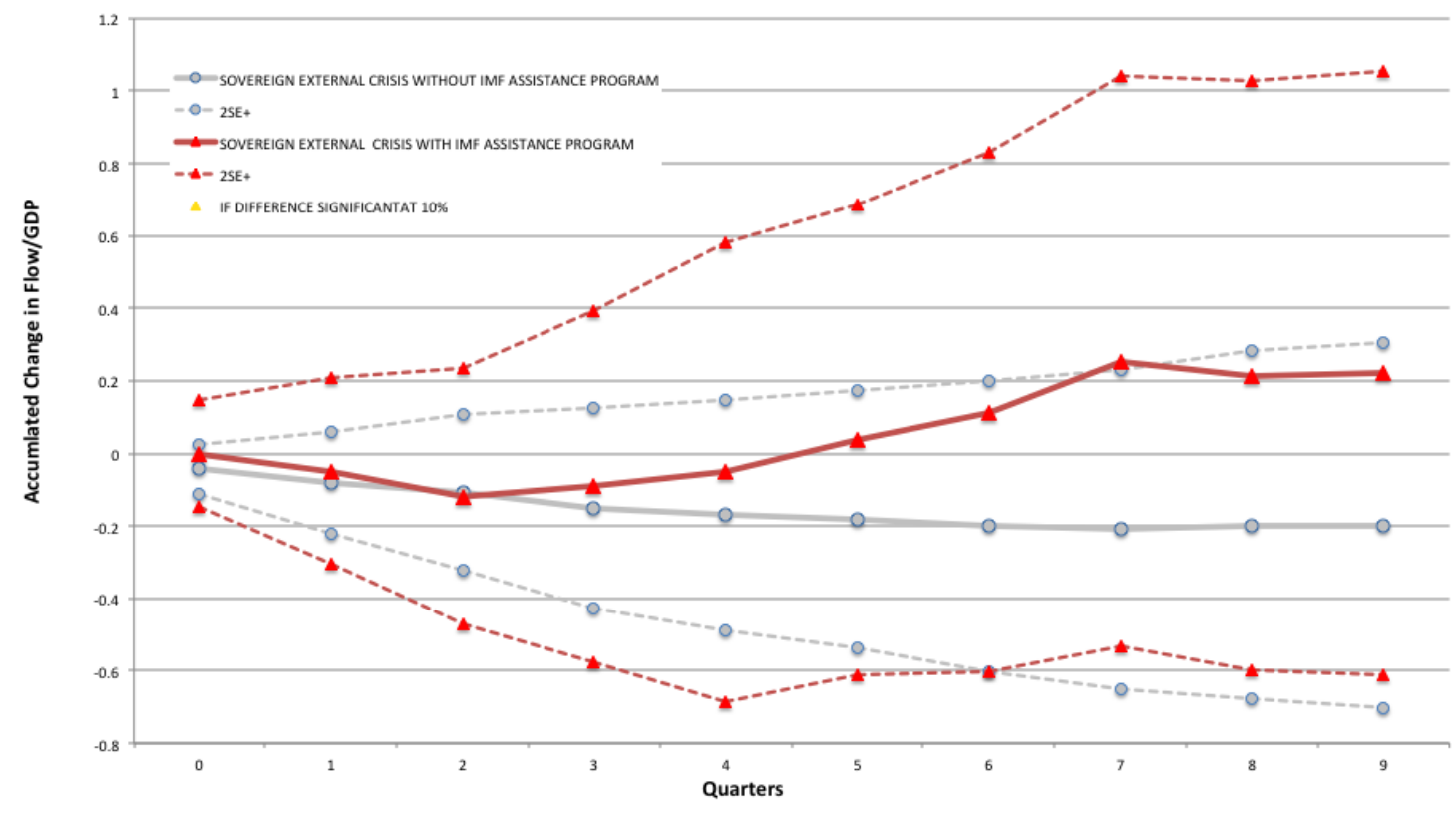

